\title{
جماليات الرواشين في هشغولات فنية برسوم الحاسب ثلاثية الأبعاد
}

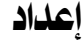 \\ د. إيماش حسر عبد الله المنتصر \\ أستاذ الأشغال الفنية المساعد

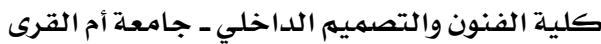

مجلة بحوث التربية النوعية ـ جامعة المنصورة

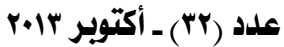




\section{جماليات الرواشين في هشغولات فنية برسوم الحاسب ثلاثية الأبعاد}

إعداد

* . إبمازخسنزعبد اللهّالمنتصر

الاقدمهة وهشكالة البحث :

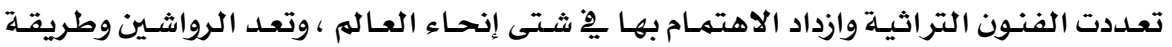

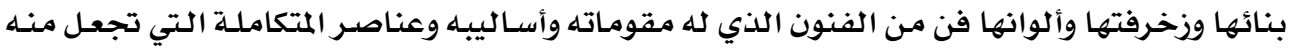

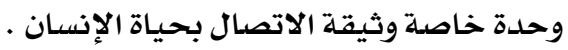

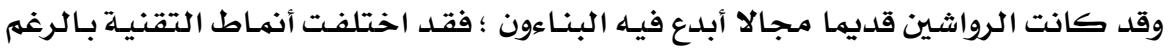

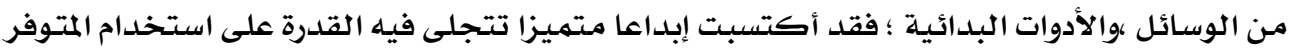

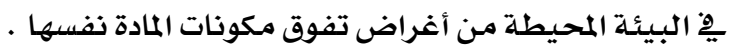

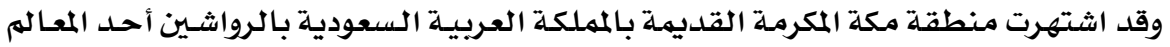

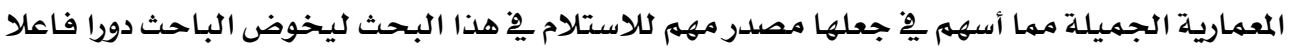

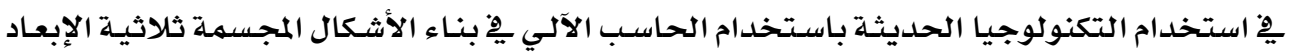

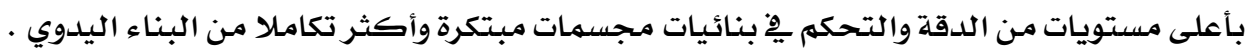
وِِِ دراسة المرحم (1990م ) أن العصر الحديث منذ بداية القرن العشرين بعد الحـرب العالميـة

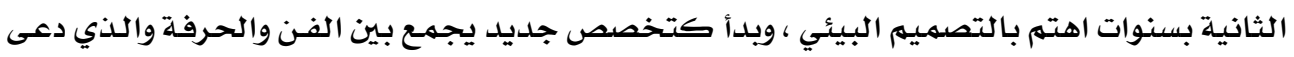

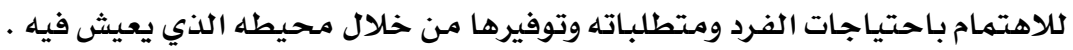

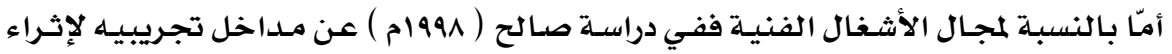

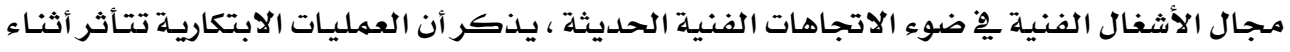

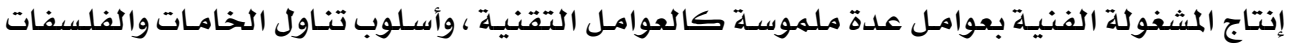

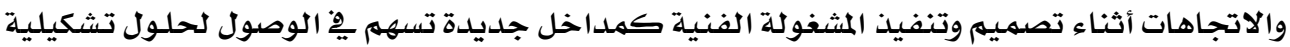
تتسهم بالجرأة والحداثة لإثراء مجاء أناء الأشغال الفنية .

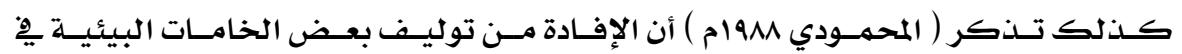

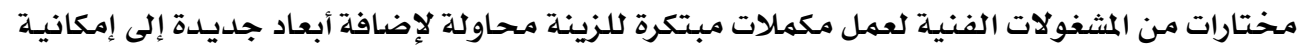

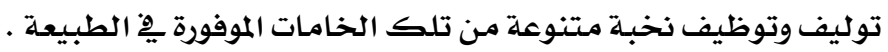

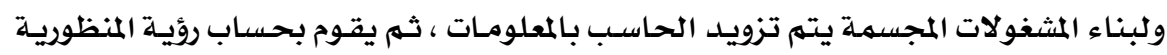

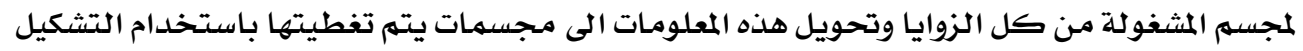




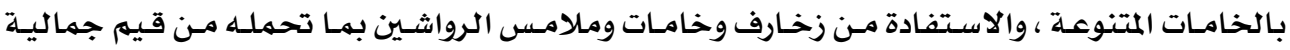

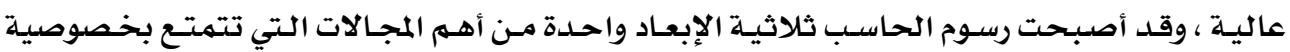

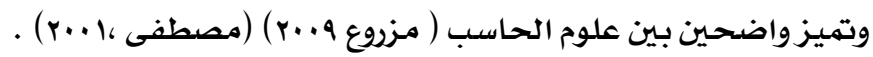

مما سبق وجدت الباحث أهمية دراسة جماليات الرواشين ِِّ ابتكار مشغولات فنية باستخدام رسوم الحاسب ثلاثية الإبعاد .

\section{ويمكن صياغة المشكلة يِ التساؤلات الآتية :}

ا ـ ما مدى أهمية استخدام الرواشين لتحقيق مشغولة فنية مبتكرة ؟

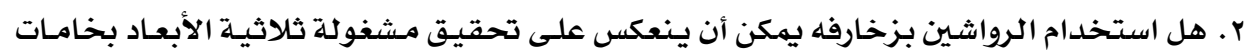

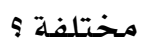
r. هل يمكن تصميهم مشغولات مستحدثة بروئ تراثية محققة الجانب الجمالي والوظيفي؟

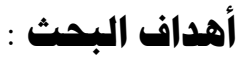

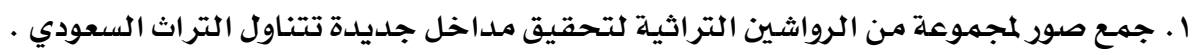

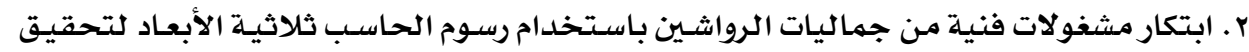

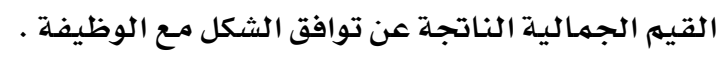

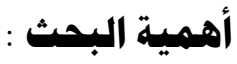

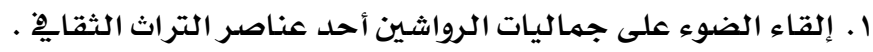

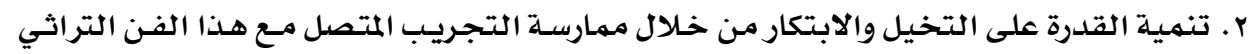

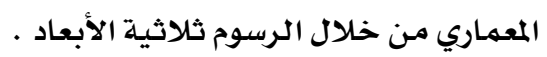

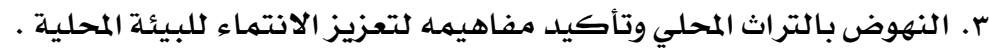

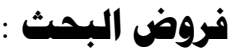

ا ـ مـا إمكانية تصميم مشغولات مبتكـرة مـن جماليـات الرواشـين باستخدام رسـوم الحاسبـ ثلاثيـة الأبعاد وفقا لأراء المحكمين تهين

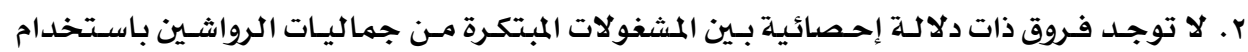

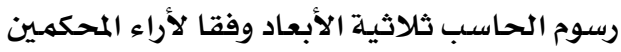

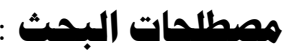
1

هو مـا يحتويـه العمل الفـني مـن سمـات وعناصـر جماليـة تميزه عن غيره نتيجـة لاستخدام

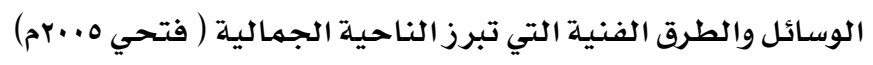


r. r. ب الرواشيز

وردت بلفظ Raushan وجمعهـا رواشـين Rawashin وهي تعريـب للكلمسة الفـارسيـة (روزن)

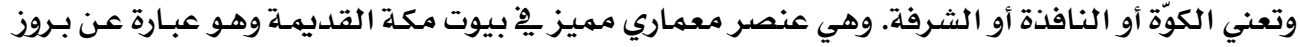

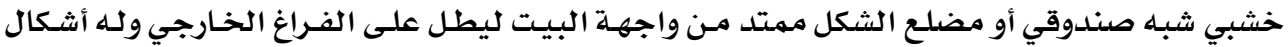

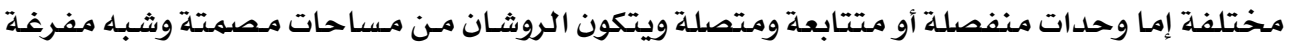

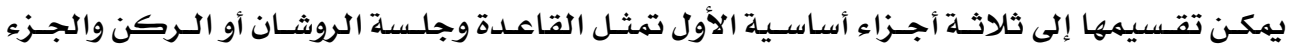

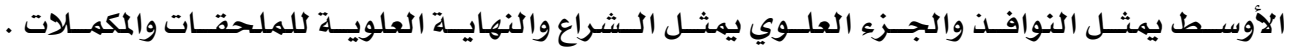

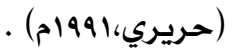

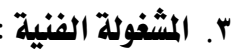

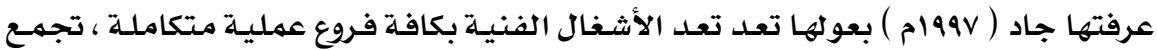

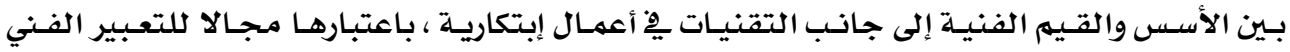

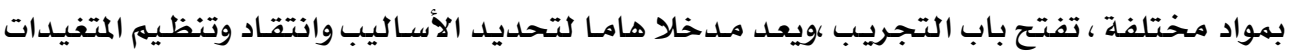

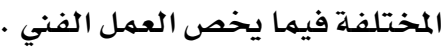

\section{؛. ثلاثية الإبعاد :}

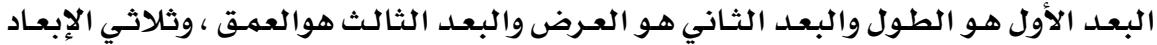

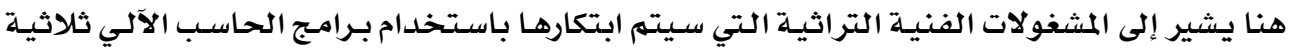

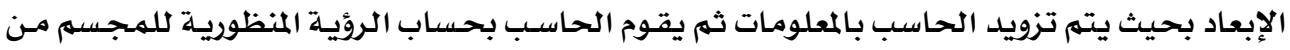

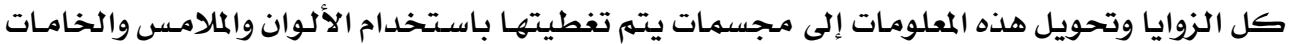

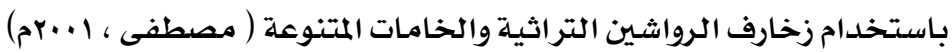

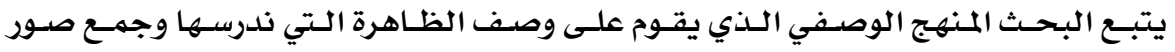

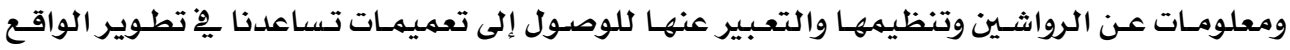

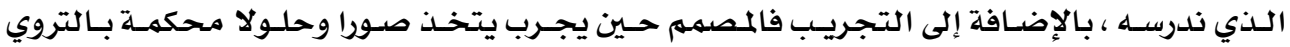

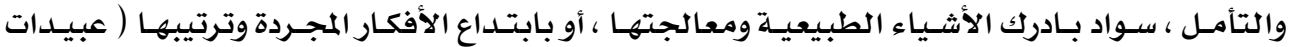

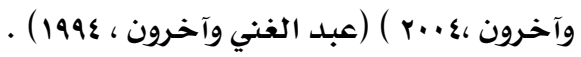

• حـدود زمـانيـة : تعـود الفـترة إلى أوائل القـرن الرابـع عشر الهجـري وأواخـر القـرن التاسـع عشر

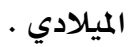
• حدود مكانية : منطقة مكة القديهة ( تشمل راوشين مكة المكرمة وجدة ). 
1. استبانه تقييم للمشفولات ثلاثية الأبعاد المبتكرة من جماليات الرواشين

وتشمل هذه الاستبانة (v) عبارات .

صدق وثبات الاستبانة

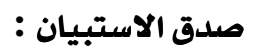

يقصد به قدرة الاستبيان على قياس ما وضع لقياسه .

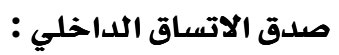

حساب معـاملات الارتبـاط بـين درجـة ككل عبـارة مـن العبـارات المكونـة للاستبيان والدرجـة

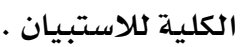

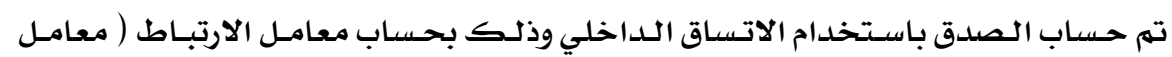

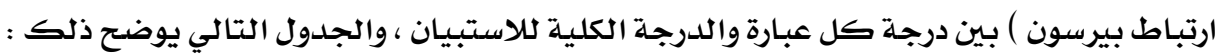

جلدول ( 1 ) قيمم معاملات الارتباط بين درجة كل عبارة والدرجة الكلية للاستبيان

\begin{tabular}{|c|c|c|c|c|c|}
\hline الدلالة & الارتباط & م & الدلاكلة & الارتباط & r \\
\hline$\cdot, \cdot 1$ & $\cdot, \wedge \wedge \wedge$ & -0 & $\cdot, \cdot 1$ & ו וג, • & -1 \\
\hline$\cdot, \cdot 1$ & $\cdot, \mathrm{V} \wedge \mathrm{V}$ & -7 & $\cdot, \cdot 1$ & $\cdot, V \cdot \varepsilon$ & $-Y$ \\
\hline$\cdot, .0$ & צrT, • & $-V$ & $\cdot, \cdot 1$ & .9Y0 & $-r$ \\
\hline & & &., 0 & $\cdot, 711$ & $-\varepsilon$ \\
\hline
\end{tabular}

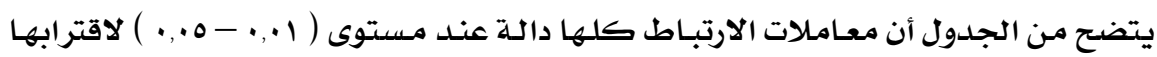
من الواحد الصديح مها يـل على صدق وتجانس عبارات الاستبيـان . انثبات :

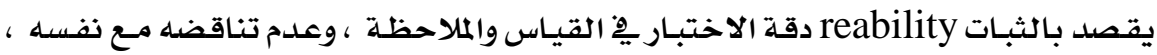

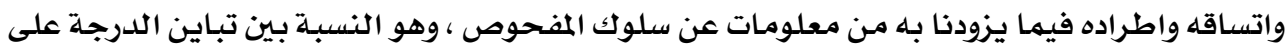

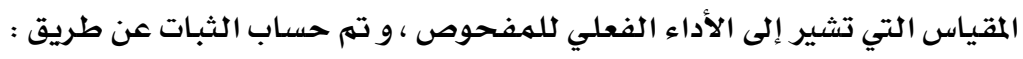

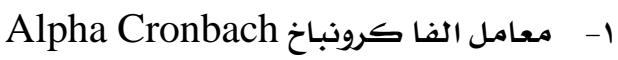
r- بريقة التجزئة النصفية Split-half جدول ( r ) قيم معامل الثبات لمحاور الاستبيان

\begin{tabular}{|c|c|c|}
\hline التجزئة النصفية & معامل الفا & \\
\hline$\cdot 917-\cdot, \Lambda \mu \mid$ & $\cdot, \Lambda \vee \varepsilon$ & ثبـات الاستبيـان ككل \\
\hline
\end{tabular}




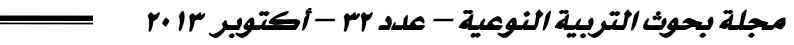

يتضـح من الجدول السـابق أن جميع قيم معاملات الثبات : معامل الفا ، التجزئة النصفية ،

دالة عند مستوى ا +,. مما يدل على ثبات الاستبيان .

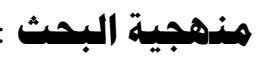

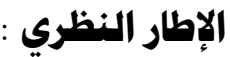

أولا : الرواشين :

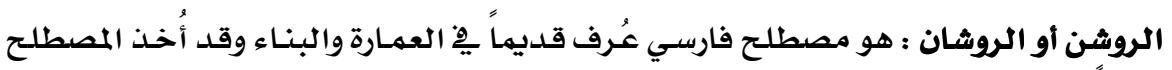

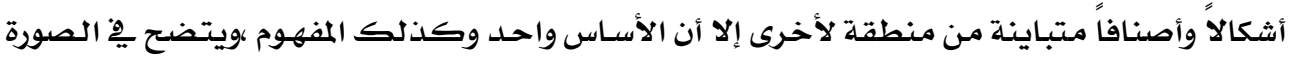

التالية رقم (1) (1)

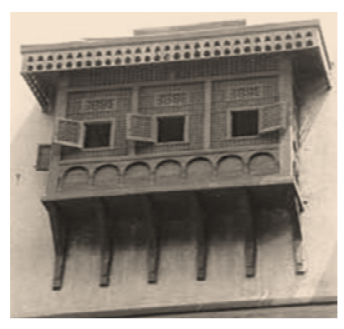

إن دخول كلمة روشن أو روشان للغة العربية ، شاع واستخدم ِِّ مجال البناء والعمارة فُعُرف

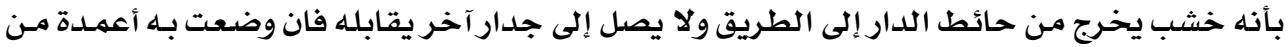

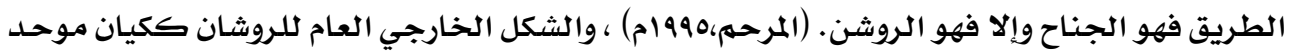

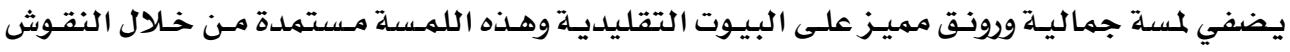

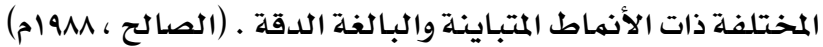

ويلتحق بالروشان حليات خشبية مكونة من وحدات زخرفية متكررة تشبـه الأهـداب تزين بها

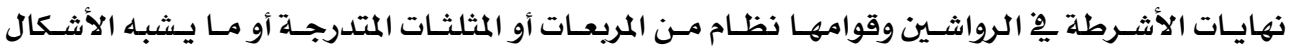

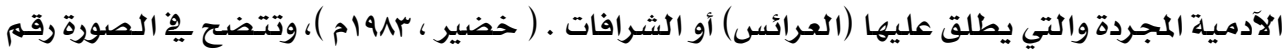

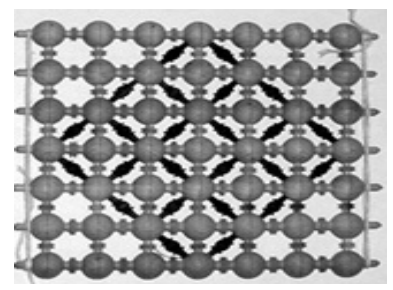

صورة رقم(r) حلية خشبية

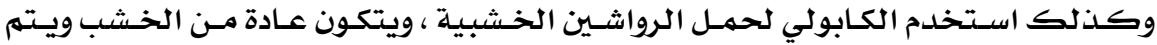

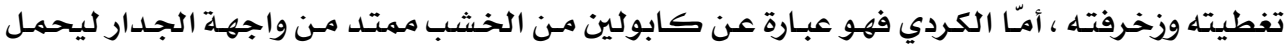




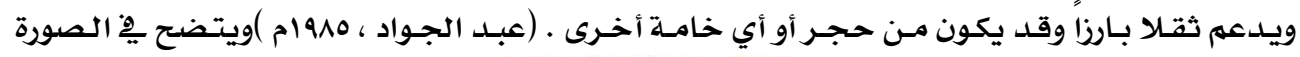

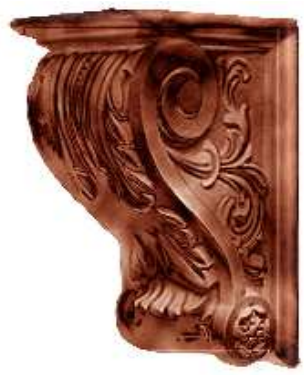

رقم(r)

$$
\text { صورة رقم (r) الكابولي }
$$

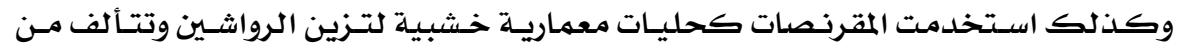

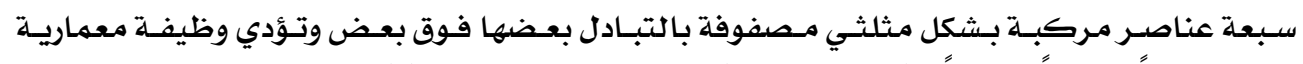

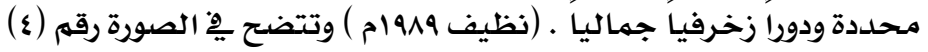
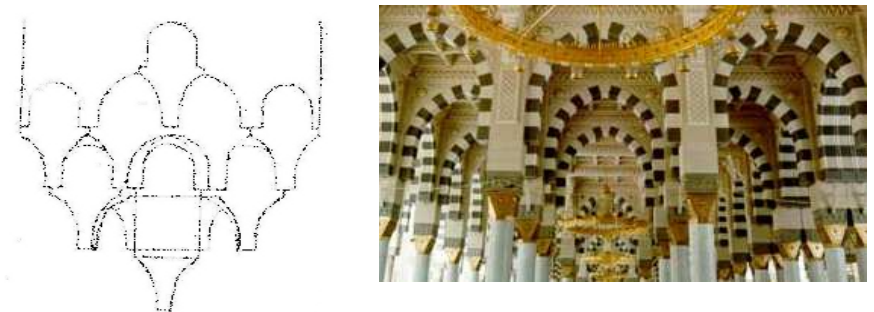

$$
\text { صورة رقم (ع) المقرنصات }
$$

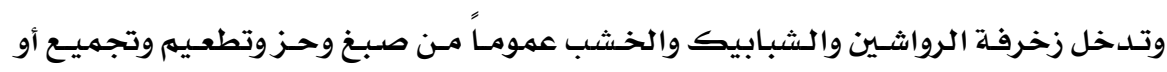

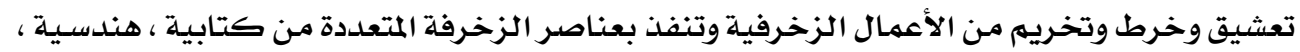

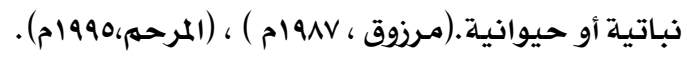

ثانيا : ثبانيا

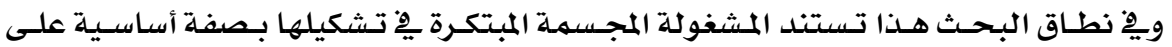

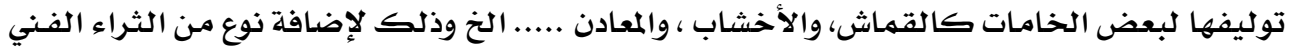

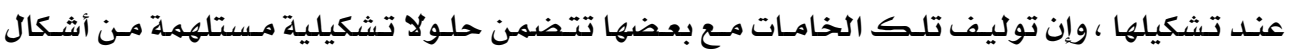

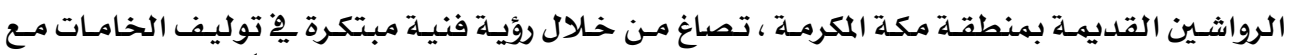

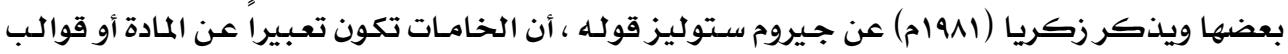

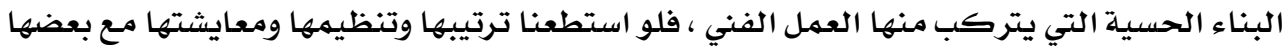

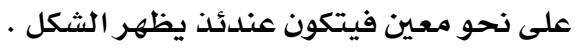

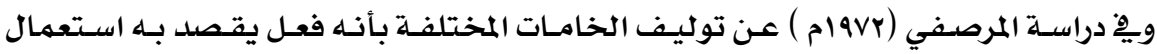

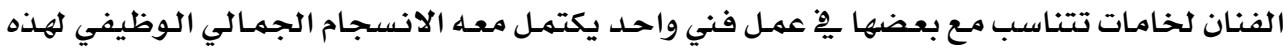

\section{$r . \Lambda$}




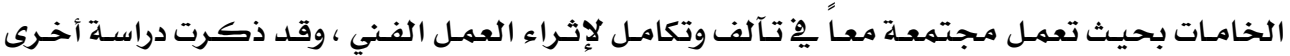

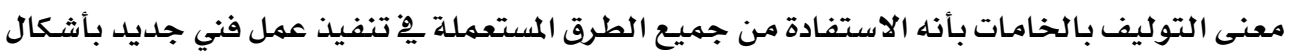

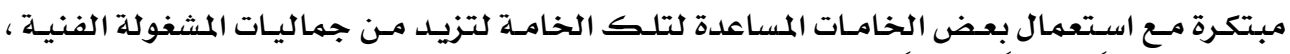

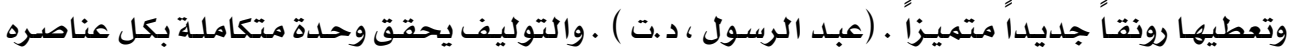

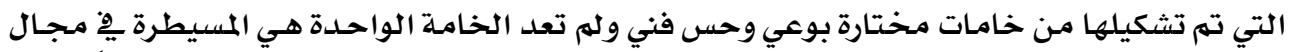

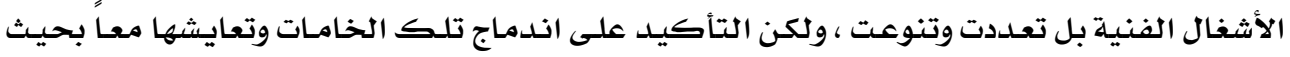

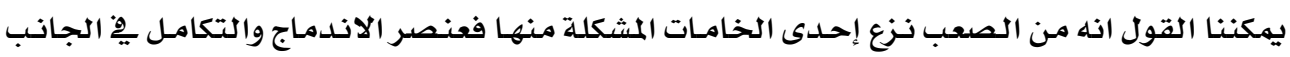

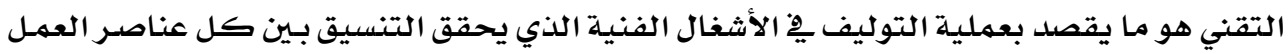

ثالثا : تقنيات بناء الأشكال ثلاثية الأبعاد :

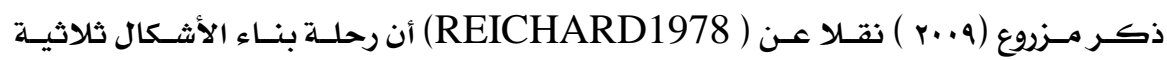

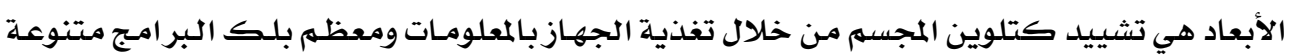

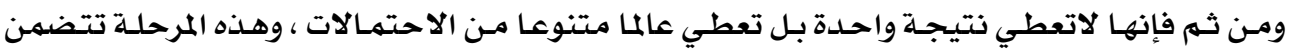

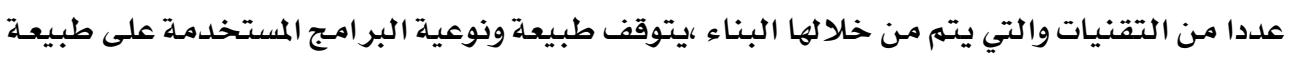

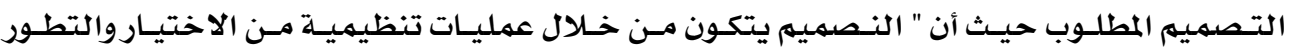

(BeVlinu.1970)

ويمكن تقسيه تقنيات بناء الأشكال ثلاثية الأبعاد إلى قسمـين :

أ - تقنيات أساسية :

وهذه التقنيات تهتم ببنـاء الشكل الثلاثي الأبعـاد الأولـي سـواء مـن الفـراغ ، مـن شكل ثنـائي الأبعاد .

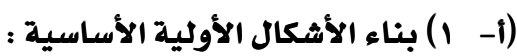

تهتم هذه التقنية ببناء المجسمات الهندسية الأولية كالمكعب والهرم ... الخخ ،

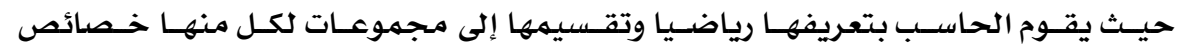

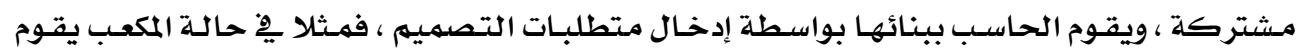

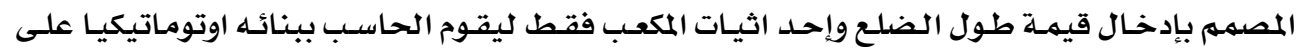

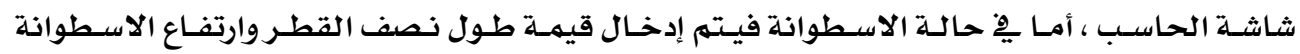

وإحداثياتها .

: r (i)

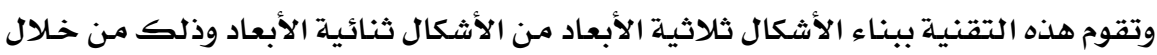

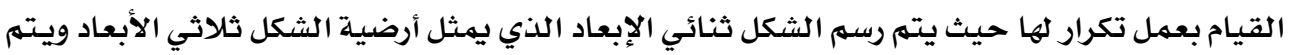

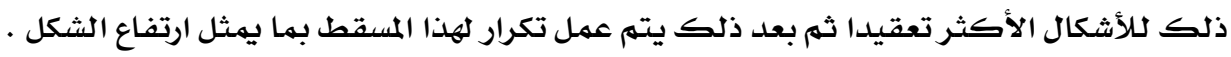


تستخدم هذه التقنية لإنتاج أشكال ثلاثية الأبعاد متماثلة حول محورها عن طرق الدوران ،

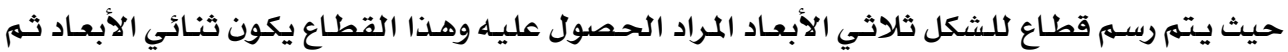

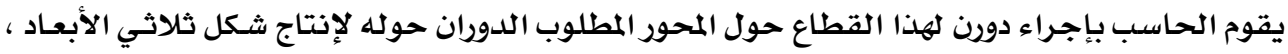

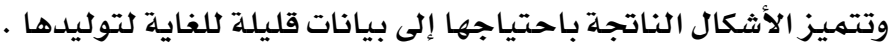
ب- تقنيات مساعدة :

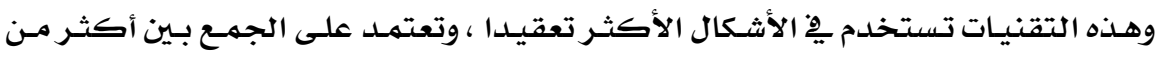

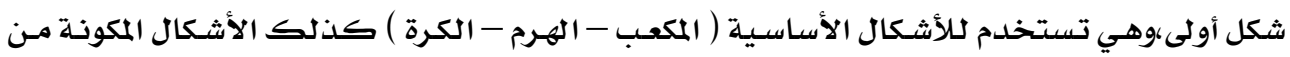

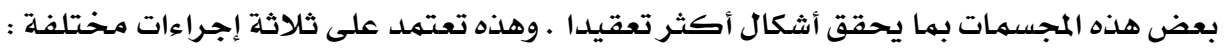

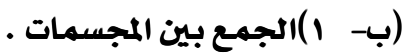

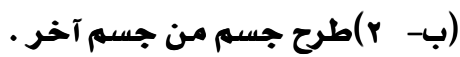

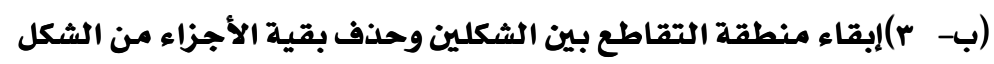

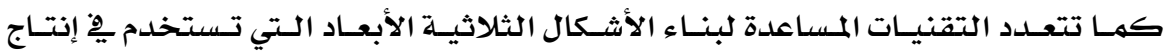

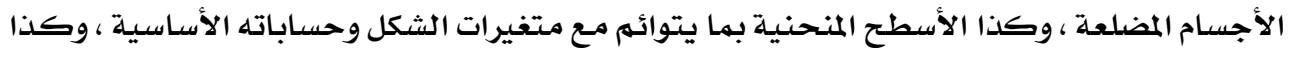

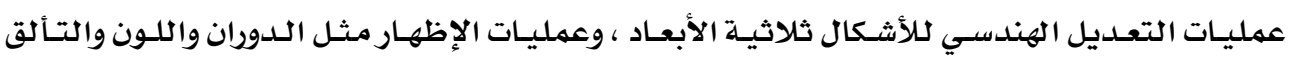

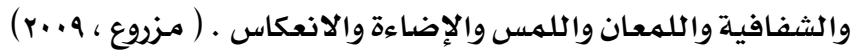

تم استخدام رسوم الحساسب الآلي ثلاثيـة الأبعـاد يِّا ابتكار مجموعـة مـن المشغولات المجسمـة

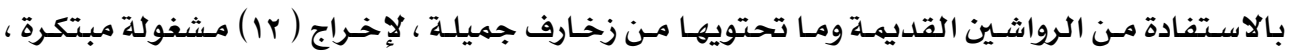
نستعرضها كالتالي : 


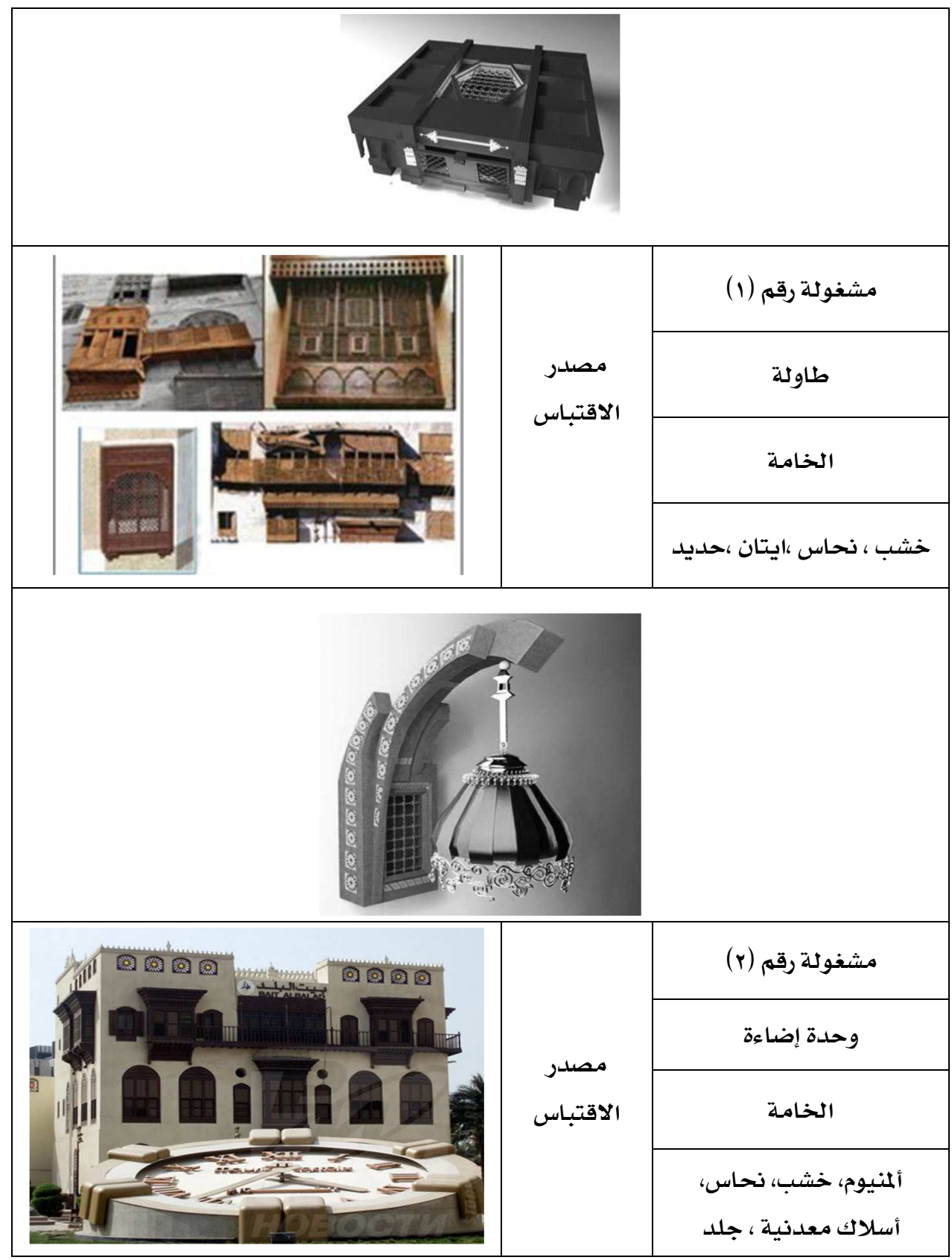




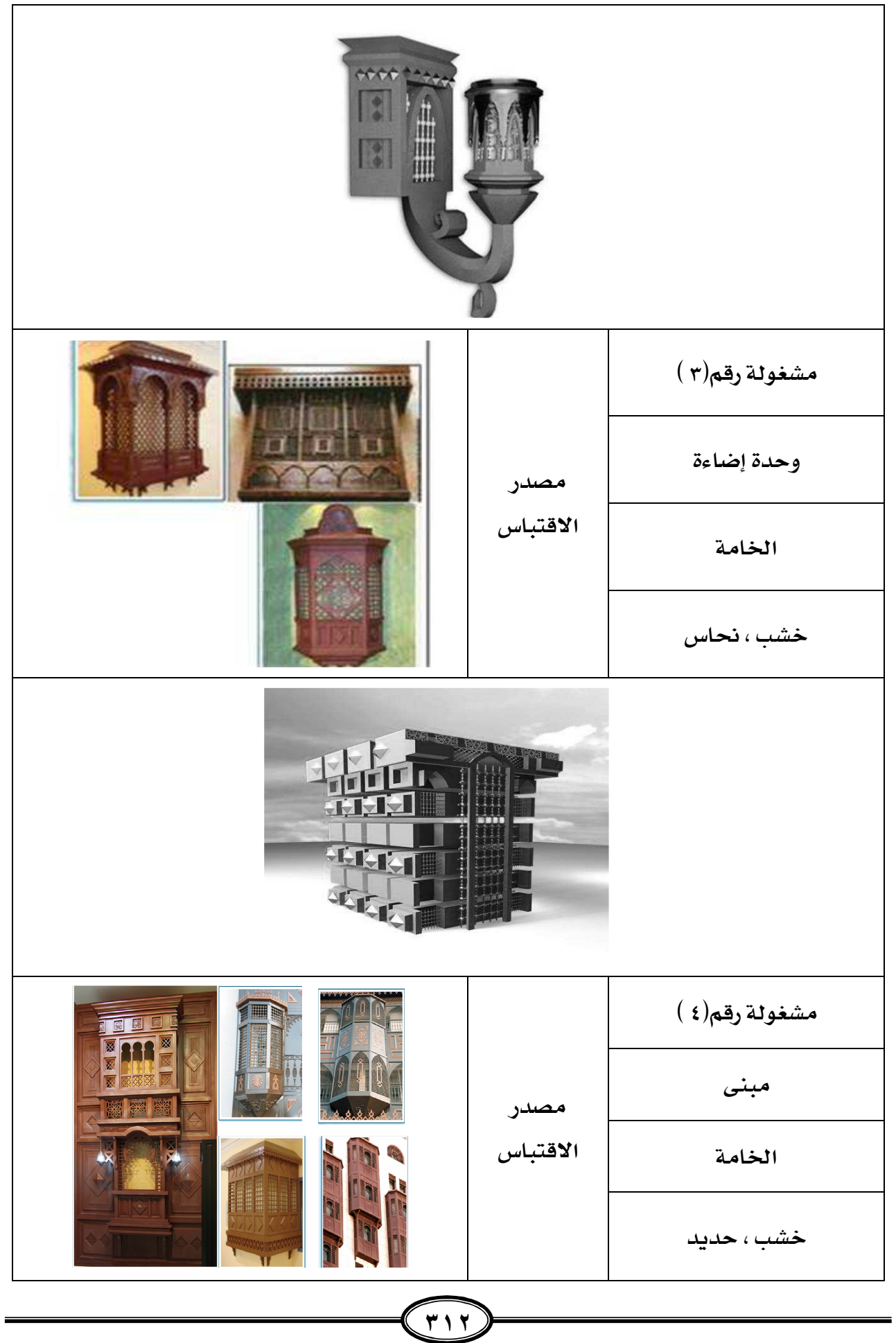




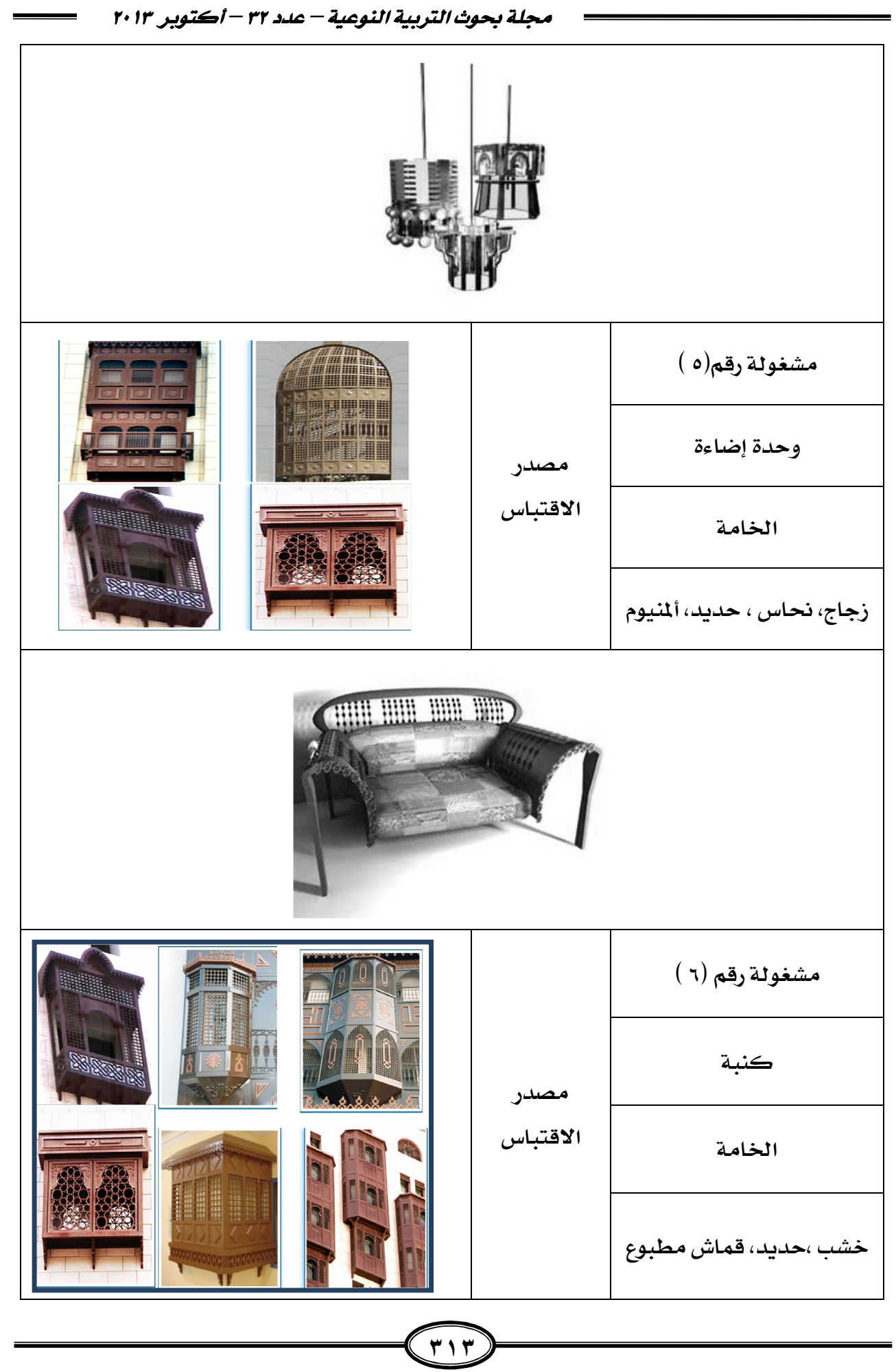




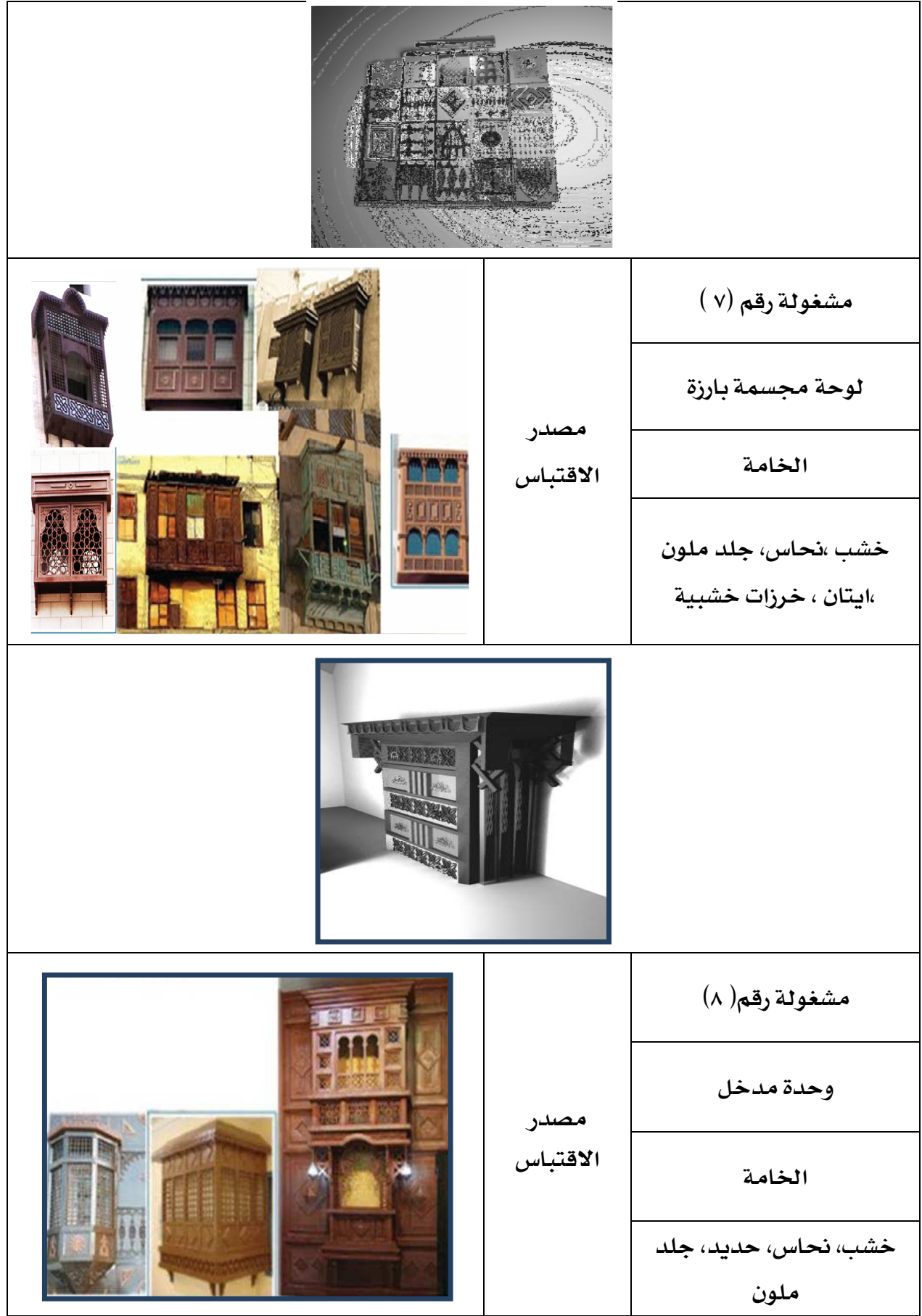




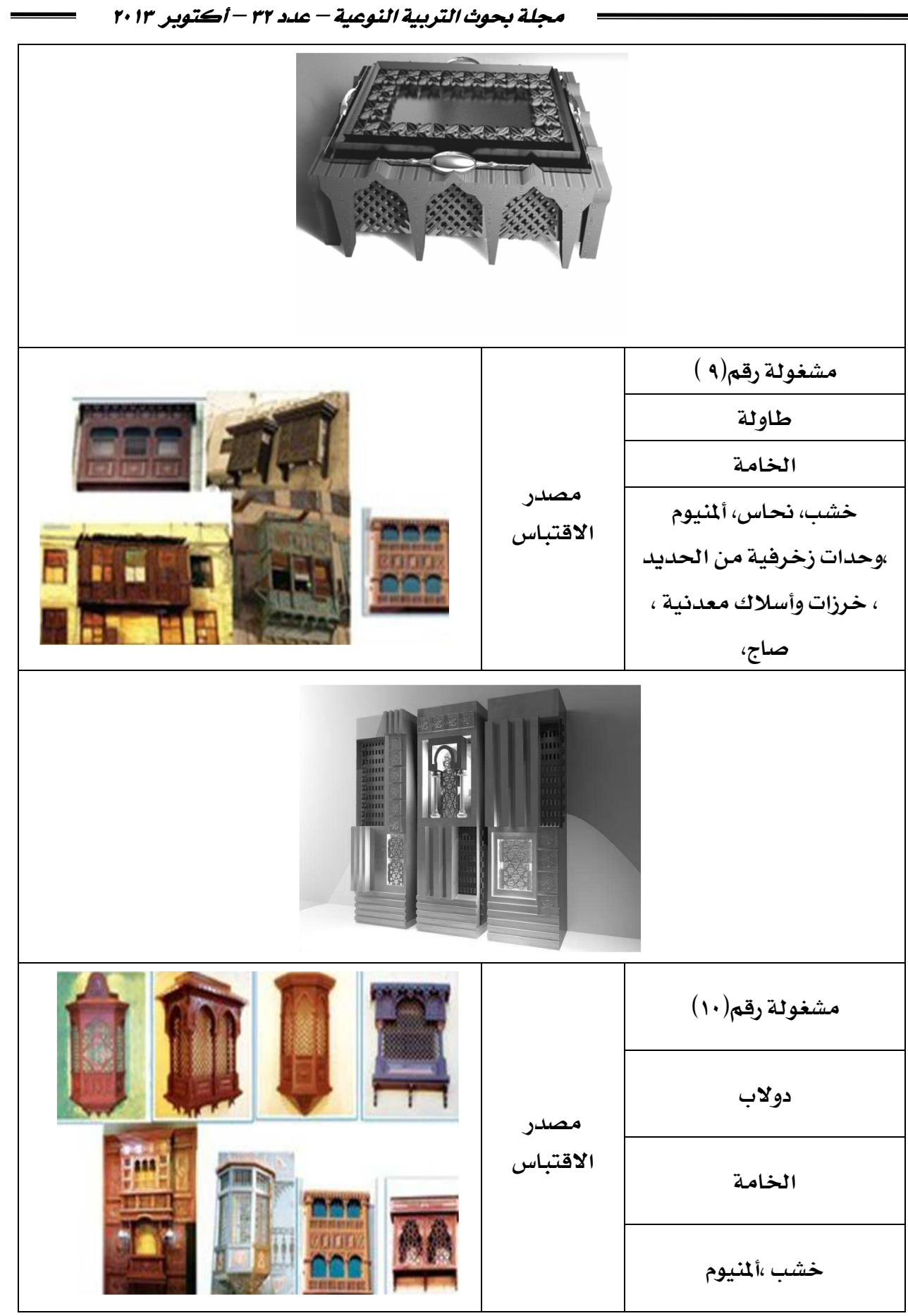




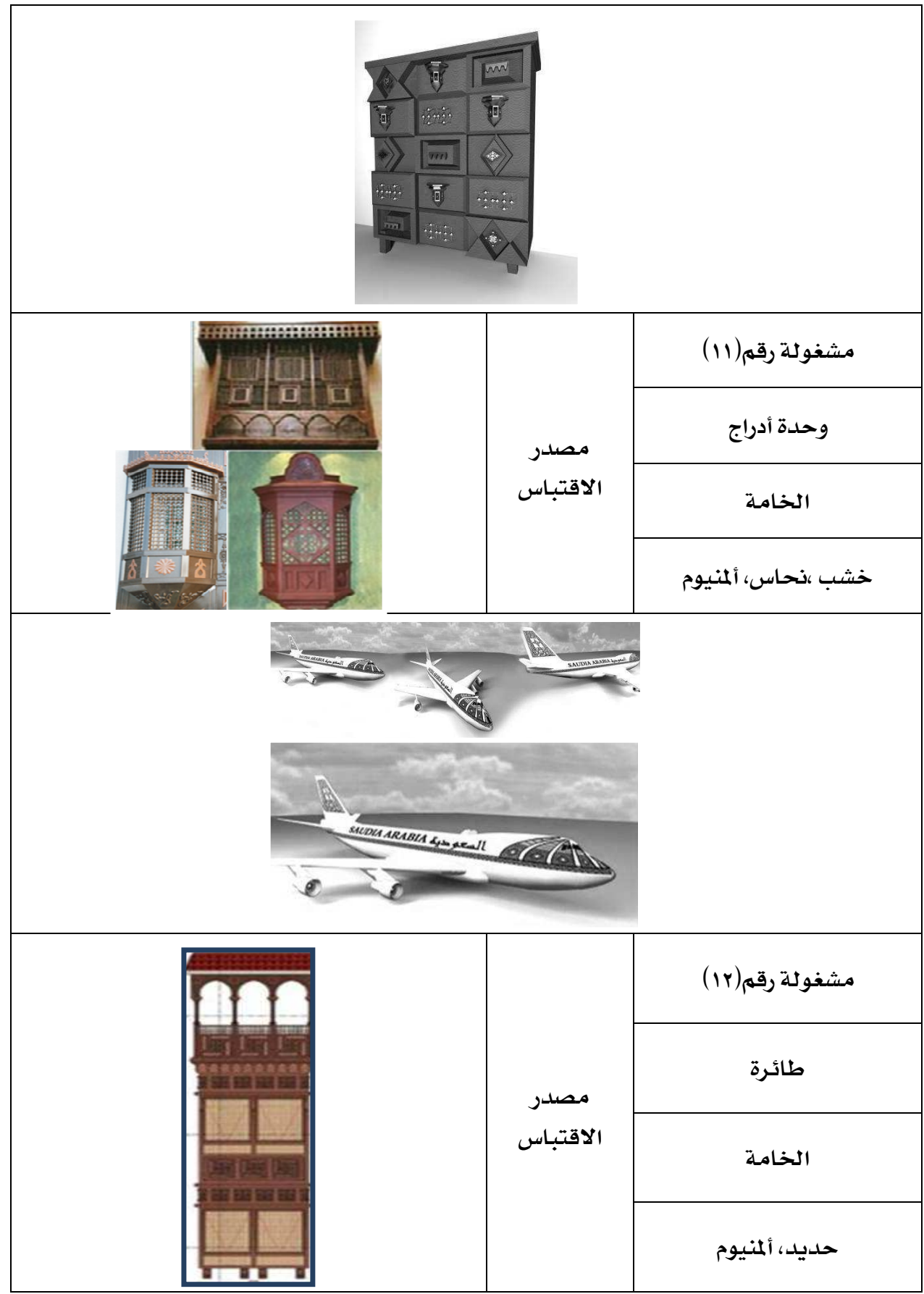




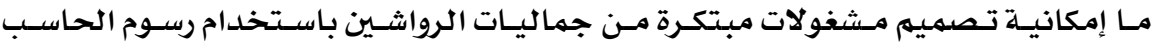
ثلاثية الأبعاد وفقا لأراء المحكمـين

وللتحقق من هذا الفرض تم حساب معاملات الجودة والمتوسط الكوزنى للمششغولات المبتكرة

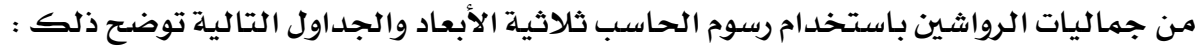
التصميم الأول : من جمات الترات

جدول (r)يوضح تكرارات إجابات المحكمين لجميع بنود تقييم التصميم الأول

\begin{tabular}{|c|c|c|c|c|c|c|c|c|}
\hline \multirow{2}{*}{ 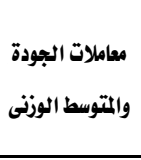 } & \multicolumn{3}{|c|}{ 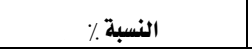 } & \multicolumn{3}{|c|}{ 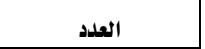 } & \multirow[b]{2}{*}{ 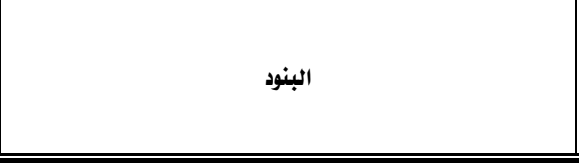 } & \multirow[b]{2}{*}{$\rightarrow$} \\
\hline & غير |- موافق & مدوافق إلى & 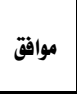 & |غير | موافق & مدافق إلى & موافق & & \\
\hline$\% 97, v$ & $\%$ & $\%$ & $/ 9 \%, r r$ & · & 1 & is & أظهرت رسوم الحاسب ثلاثية الأبعاد جماليات الرواشين على الششفولات & -1 \\
\hline 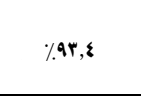 & $\%$ & $\%$ & $\%$ /AT, १V & · & r & ir & | في تصميم مشفولات مستحدثه الشفولة الاستفادة من إمكانيات رسوم الحاسب الآلي ثلاثية الأبعاد & $-r$ \\
\hline$\%$ & $\%$ & $\%$ & $\%$ & . & . & 10 & | حققت الشفولة أفكارا تتسم بالابتكار والإبداع & $-r$ \\
\hline$\%$ & $\%$ & $\%$ & $\% \cdot{ }^{*}$ & . & $r$ & ir & |حققت الشغولة أس وعناصر التصميم & $\varepsilon$ \\
\hline$\% 97, v$ & $\%$ & $\%, 7,7 \mathrm{r}$ & $\%$ \% & . & 1 & $1 \varepsilon$ & | حققت الشفولة ملامس متنوعة من خلال توليف الخامات & Oـ \\
\hline 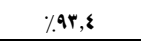 & $\%, 7 \mathrm{TV}$ & $\%, \mathrm{TV}$ & $1 / \Lambda 7, \mathrm{TV}$ & 1 & 1 & ir & | حققت الشغولة أبعادا جمالية ووظيفية & -7 \\
\hline$\%$ \%. & $\% 9,7 v$ & rT, & $\%$ /. & 1 & $r$ & ir & |تتشى الششفولة ذات الرؤى التراثية مع اتجاهات العصر الحديث & $-r$ \\
\hline
\end{tabular}

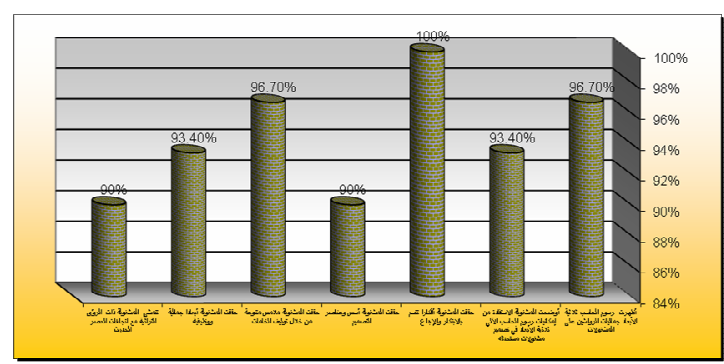

شكل (1) يوضح معاملات الجودة لجميع بنود تقييم التصميم الأول

من الشكل السابق نستخلص ما يلي :

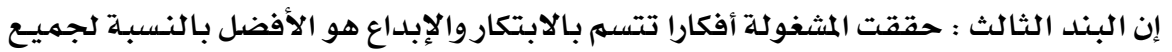

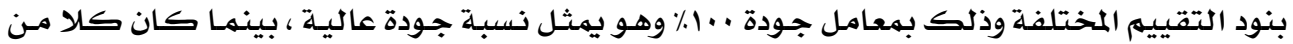

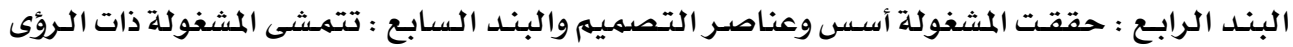

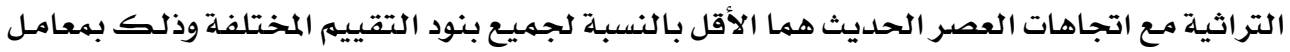


جودة • 9٪ وهما يمثلان نسبة جودة متوسطة ، ثم كالا من البند الأول : أظهرت رسـوم الحاسب ثلاثيـة

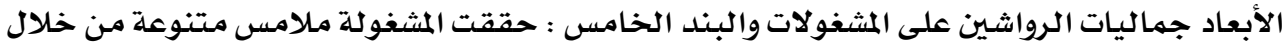

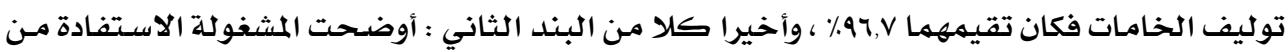

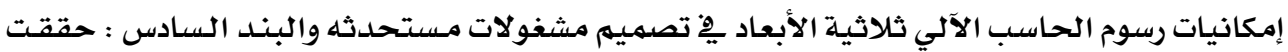

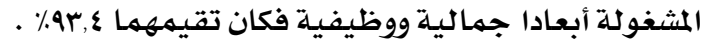

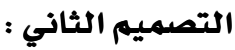
جدول(ء) يوضح تكرارات إجابات المحكمين لجميع بنود تقييم التصميهم الثاني

\begin{tabular}{|c|c|c|c|c|c|c|c|c|}
\hline \multirow{2}{*}{ والمتوسط الوزنى الجودة } & \multicolumn{3}{|c|}{ 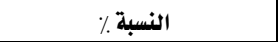 } & \multicolumn{3}{|c|}{ 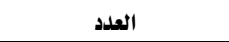 } & \multirow[b]{2}{*}{ 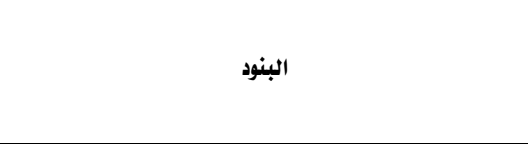 } & \multirow[b]{2}{*}{+} \\
\hline & 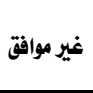 & موافق إلى & 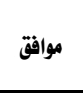 & غير & موافق إلى & 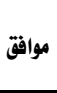 & & \\
\hline$\% 99, \vee$ & $\%$ & $\%$ \%, 7v & $\%$ & • & 1 & i\& & أظهرت رسوم الحاسب ثلاثية الأبعاد جماليات الرواشين على المشفولات & -1 \\
\hline$\% 97, \vee$ & $\%$ & $\%$ \%, १V & $\%$ qr, rr & • & 1 & is & |أوضحت الششفولة الاستفادة من إمكانيات رسوم الحاسب الآلـي ثلاثيـة & $-r$ \\
\hline$\%$ & $\%$ & $\%$ & $\%$ •. & • & $r$ & ir & |حققت الشفولة أفكارا تتسم بالابتكار والإبداع & $-r$ \\
\hline$\%$ & $\%$ & $\%$ & $\%$ & - & - & 10 & |حقت المشفولة أسس وعناصر التصميه & $\varepsilon$ \\
\hline$\%$ \% & $\%$ \%, १V & $\%$ \%, १V & $\%$ \% ฯ, ๆ & 1 & 1 & ir & |حققت الشفولة هلامس متنوعة من خلال توليف الخامات & - 0 \\
\hline$\%$ & $\%$ \% १ & $\%$ & $\%$ • & 1 & $r$ & ir & |حقت المشفولة أبعادا جمالية ووظيفية & -7 \\
\hline$\% \wedge \uparrow, \vee$ & $\% 9, \mathrm{TV}$ & $\% r$. & $\%$ rr, r & 1 & $r$ & 11 & تتمشى المشفولة ذات الرؤى التراثية مع اتجاهات العصر الحديث & $-\mathrm{r}$ \\
\hline
\end{tabular}

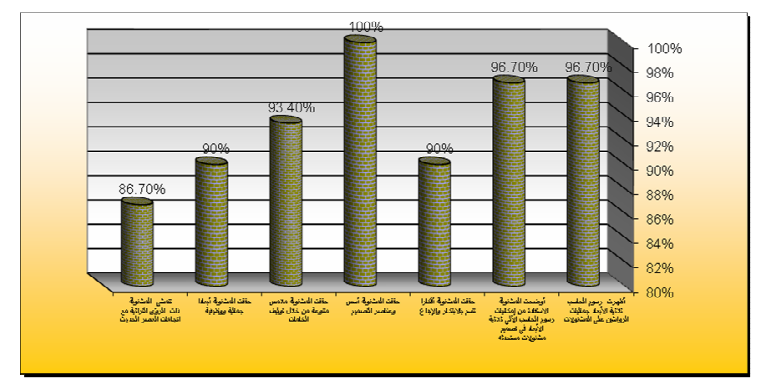

$$
\begin{aligned}
& \text { شكل(ץ) يوضح معاملات الجودة لجميع بنود تقييم التصميم الثاني } \\
& \text { من الشكل السابق نستخلص ما يلي : }
\end{aligned}
$$

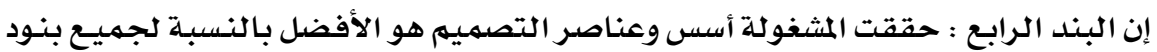

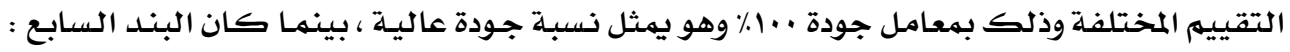

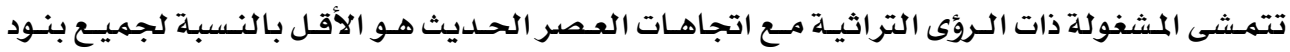

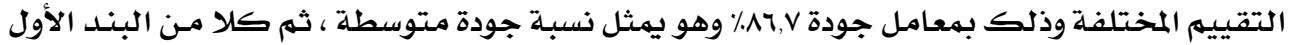

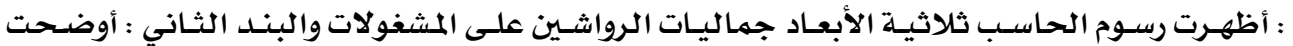


المثغولة الاستفادة من إمكانيـات رسـوم الحاسب الآلي ثلاثيـة الأبعـاد ِِِ تصميم مشغولات مستحدثـه

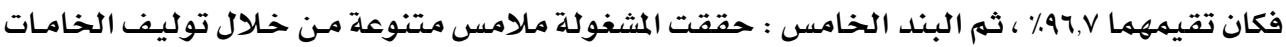

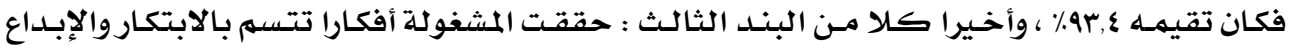

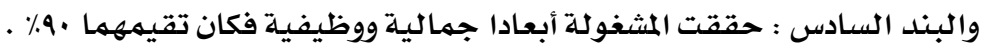
التصميم الثالث :

جدول (ه)يوضح تكرارات إجابات المحكمين لجميع بنود تقييم التصميم الثالث

\begin{tabular}{|c|c|c|c|c|c|c|c|c|}
\hline \multirow{2}{*}{ | مالمقاملات الجودة } & \multicolumn{3}{|c|}{ النسبة. } & \multicolumn{3}{|c|}{ العدد العد } & \multirow[b]{2}{*}{ البنود ال } & \\
\hline & غير موافق & موافق إلى & موافق & غواقيز & موافق إلى & 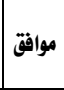 & & $\rightarrow$ \\
\hline$\%$ & $\%$ & $\%$ & $\%$ & . & - & 10 & أظفهرت رسوم الحاسب ثلاثيـة الأبعاد جماليـات الرواشين على & \\
\hline$\% 97,4$ & $\%$ & $\%, 1 \mathrm{TV}$ & $\%$ \% & . & 1 & $1 \varepsilon$ & | ثلاثية الأبعاد في تصعيم مشفولات مستحدثة الاستفادة مـن إمكانيسات رسوم الحاسب الآلسي & \\
\hline$\% 97, v$ & $\%$ & $\%, 7 \mathrm{qr}$ & $\%$ \% & . & 1 & $1 \xi$ & | حققت الشفولة أفكارا تتسم بالابتكار والإبداع & r \\
\hline$\%$ \% & $\%$ & $\%$ & $\%$ \% $1 \mathrm{~T}, \mathrm{TV}$ & . & r & ir & حققت الششفولة أس وعناصر التصبيم & كـ \\
\hline$\%$ & $\%$ & $\%$ & $\%$ & . & - & 10 & |حققت الشفولة ملامس متنوعة من خخلال توليف الخامات & ـ \\
\hline$\%$ & $\%, 7,7 \mathrm{~V}$ & $\%$ & $\%$. & 1 & $r$ & ir & | حققت الششفولة أبعادا جمالية ووظيفية & -1 \\
\hline$\% 97, v$ & $\%$ & $\%, 7 \mathrm{qr}$ & $\%$ \% & - & 1 & $1 \mathfrak{\varepsilon}$ & تتشى الششفولة ذات الرؤى التراثية مع اتجاهات العصر الحديث & $-v$ \\
\hline
\end{tabular}

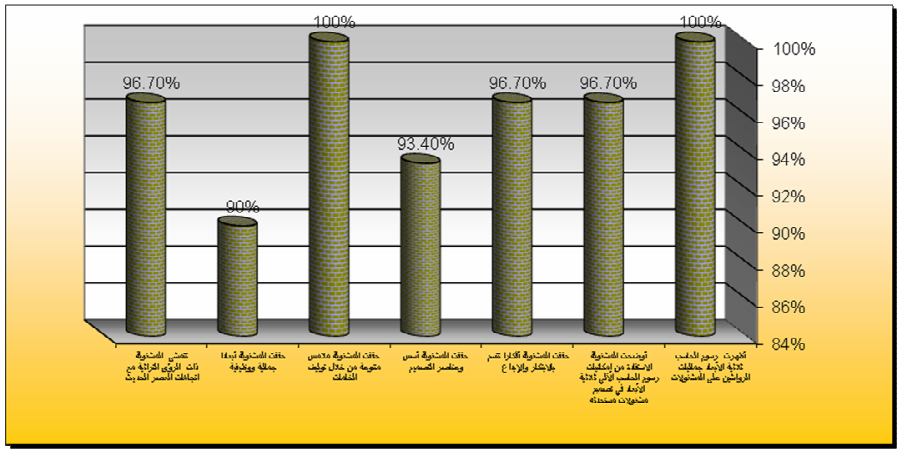

شكل(r) يوضح معاملات الجودة لجميع بنود تقييم التصميم الثالث من الشكل السابق نستخلص ما يلي :

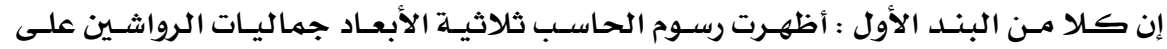

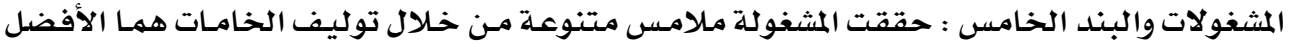

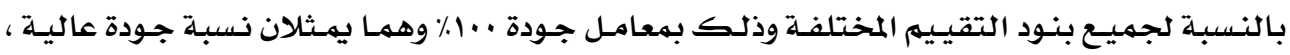


بينما كان البنـد السادس : حققت المشغولة أبعـادا جماليـة ووظيفيـة هو الأقل بالنسبة لجميـع بنـود

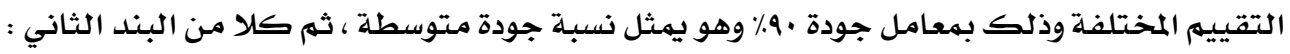

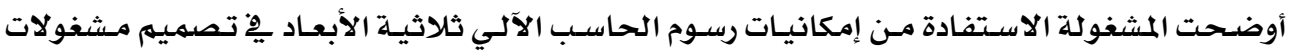

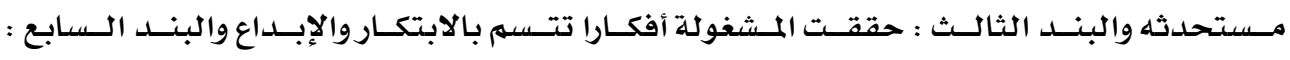

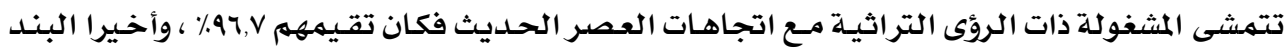

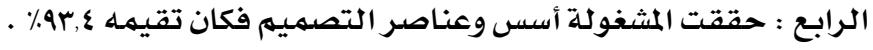
التصميم الرابع :

جدول(ج) يوضح تكرارات إجابات المحكمين لجميع بنود تقييم التصميم الرابع

\begin{tabular}{|c|c|c|c|c|c|c|c|c|}
\hline \multirow{2}{*}{ مالمتوسط الوزات الجودة } & \multicolumn{3}{|c|}{ 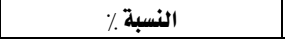 } & \multicolumn{3}{|c|}{ العلد } & \multirow[b]{2}{*}{ 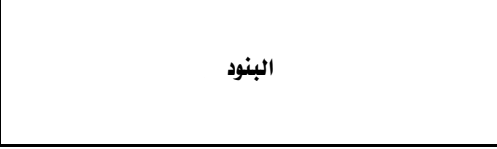 } & \multirow[b]{2}{*}{$\rightarrow$} \\
\hline & غير موافق & موافق إلى & 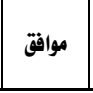 & غير & موافق إلى & 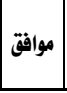 & & \\
\hline$\%$ & $\%$ & $\%$ & $\%$ & • & • & 10 & أظهرت رسوم الحاسب ثلاثيـة الأبعـاد جماليـات الرواشـين على | & -1 \\
\hline$\%$ & $\%$ ฯ १V & $\%$ \% १ & $\% \wedge \uparrow$, १V & 1 & 1 & IT & أوضحت الششفولة الاستفادة مـن إمكانيـات رسـوم الحاسب الآلـي & $-r$ \\
\hline$\%$ & $\%$ \%, ๆv & $\%$ & $\%$. & 1 & $r$ & ir & حققت المشفولة أفكارا تتسم بالابتكار والإبلداع & r \\
\hline$\%$ ^^, $\vee$ & $\% 7,7 \mathrm{~V}$ & $\%$ & $\% \mathrm{Vr}, \mathrm{rr}$ & 1 & r & 11 & حققت الششفولة أسس وعناصر التصميم & $\varepsilon$ \\
\hline$\%$ \% & $\%$ Ir, rr & $\%$ & $\% 97,7 \mathrm{v}$ & $r$ & $r$ & 1. & حققت المشفولة ملامس متنوعة من خلال توليف الخامات & -0 \\
\hline$\%$ & $\%$ & $\%$ & $\%$ •. & • & r & ir & حققت المشفولة أبعادا جمالية ووظيفية & -7 \\
\hline$\%$ \% ६ ६ & $\%$ & $\%$ & $\% \wedge \uparrow, 7 \vee$ & - & r & ir & تتمشى الشفولة ذات الرؤى التراثية مع اتجاهات العصر الحديث & $-r$ \\
\hline
\end{tabular}

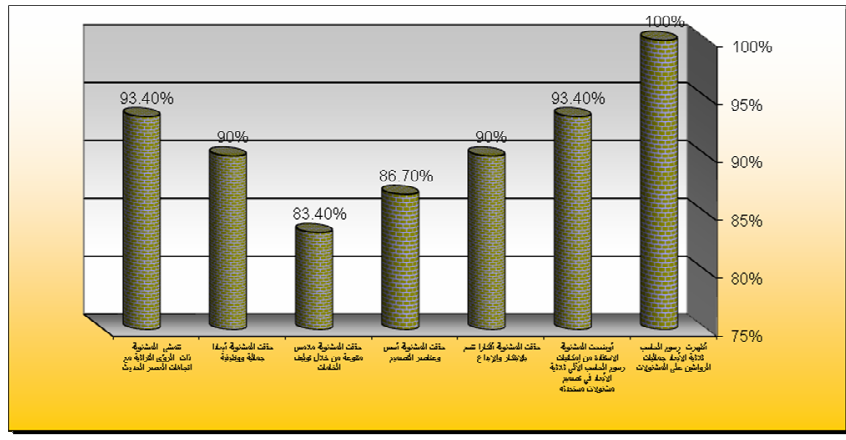

شكل(ع) يوضح معاملات الجودة لجميع بنود تقييم التصميم الرابع

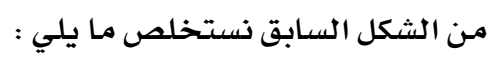

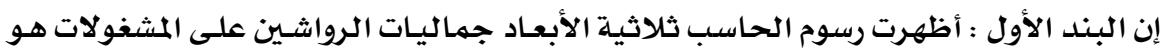

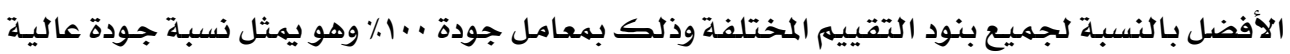


، بينمـا كـان البنـد الخـامس : حققت المشغولة ملامس متتوعة مـن خـلال توليف الخامـات هو الأقل

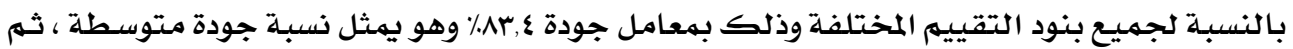
كلا من البند الثاني : أوضحت المثغولة الاستفادة مـن إمكانيـات رسـوم الحساسب الآلـي ثلاثيـة الأبعـاد

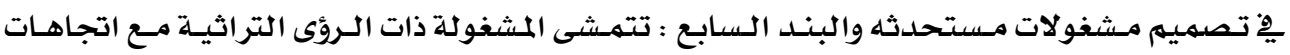

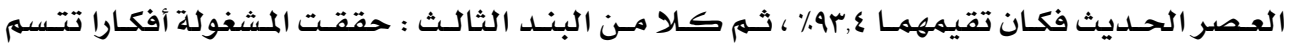

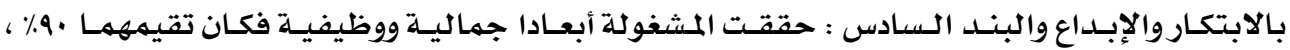

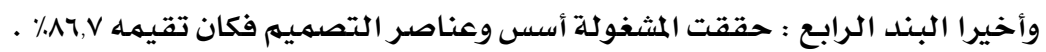
التصميم الخامس :

جدول (v) يوضح تكرارات إجابات المحكمين لجميع بنود تقييم التصميهم الخامس لئ

\begin{tabular}{|c|c|c|c|c|c|c|c|c|}
\hline \multirow{2}{*}{ مالمتوسطات الجودة } & \multicolumn{3}{|c|}{ 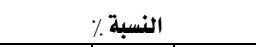 } & \multicolumn{3}{|c|}{ 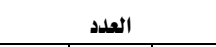 } & \multirow[b]{2}{*}{ 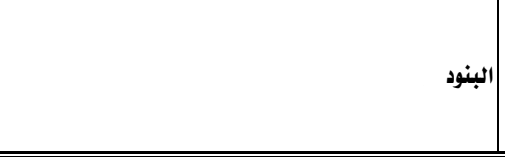 } & \multirow[b]{2}{*}{+} \\
\hline & 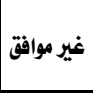 & موافق إلى & 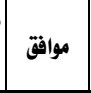 & غوافق & |موافق إلى & مواقق & & \\
\hline$\% 97, \vee$ & $\%$ & $\%\urcorner, 7 v$ & $\%$ qr, rr & • & 1 & $1 \varepsilon$ & | ألظهرت رسوم الحاسب ثلاثيـة الأبعـاد جماليـات الرواشـين على & -1 \\
\hline$\% 97, \vee$ & $\%$ & $\%$ \% $7 v$ & $\%$ /qr, rr & • & 1 & $1 \varepsilon$ & | ثأوضحت الشفولة الاستفادة مـن إمكانيـات رسـوم الحاسب الآلـي & -4 \\
\hline$\%$ \% ६ ६ & $\%$ & $\%$ & 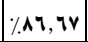 & - & $r$ & ir & |حقت المشفولة أفكارا تتسم بالابتكار والإبداع & $-r$ \\
\hline$\%$. & $\%$ \%, १V & $\%$ & $\%$. & 1 & r & ir & |حقت الشفولة أسس وعناصر التصميي & $\varepsilon$ \\
\hline$\%$ \% ६ ६ & $\%$ \%, १V & $\%$ \% १४ & $\% \wedge \uparrow, 7 \mathrm{~V}$ & 1 & 1 & ir & ]حقت الششفولة هلامس متنوعة من خلال توليف الخامات & ـ \\
\hline$\% 97, Y$ & $\%$ & $\%$ \% $7 \mathrm{Y}$ & $\% 9 r, r r$ & - & 1 & $1 \xi$ & |حقت الشفولة أبعادا جمالية ووظيفية & -7 \\
\hline$\%$ & $\%$ & $\%$ & $\%$ & . & . & 10 & |تتمشى المشفولة ذات الرؤى التراثية مع اتجاهات العصر الحديث & $-\gamma$ \\
\hline
\end{tabular}

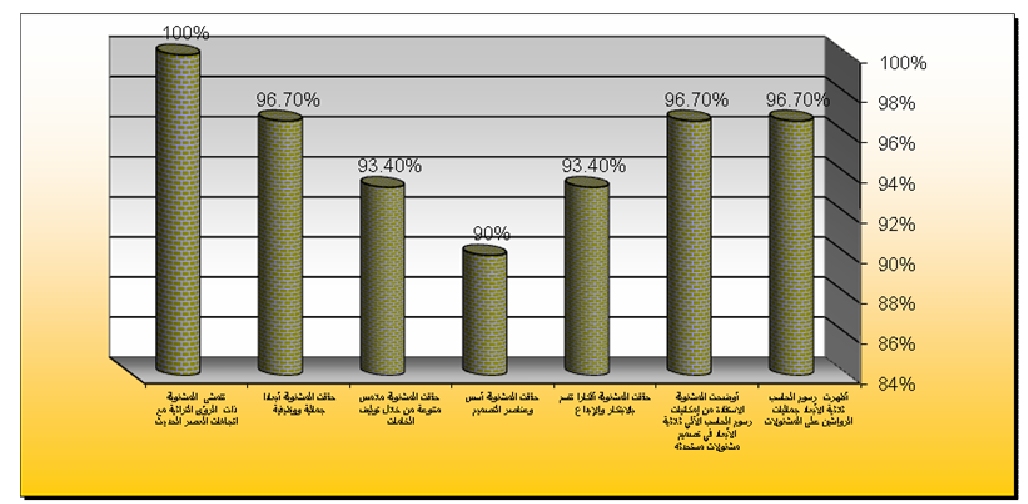

شكل (ه) يوضح معاملات الجودة لجميع بنود تقييم التصميم الخامس من الشكل السابق نستخلص ما يلي : 


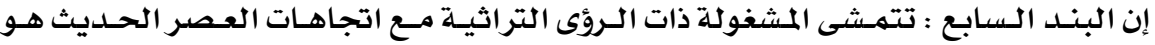

الأفضل بالنسبـة لجميع بنود التقييهم المختلفة وذلك بمعامل جودة ـ . 1٪ وهو يهثل نسبـة جـودة عاليـة

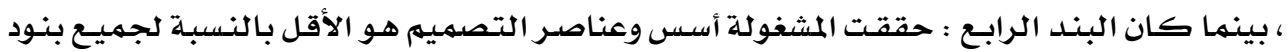
التقييم المختلفة وذلك بهعامل جودة • 9٪ وهو يهثل نسبـة جودة متوسطة ، ثم كالا مسن البند الأول : أظهـرت رسـوم الحـاسبـ ثلاثيـة الأبعـاد جماليـات الرواشـين علـى المشغولات والبنـــ الثـاني : أوضسحت

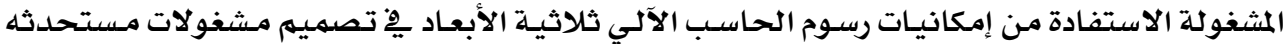
والبند السادس : حققت المشغولة أبعادا جمالية ووظيفية فكان تقيههم V7,V٪ ، وأخيرا كـلا مـن البند الثالث : حققت المشغولة أفكارا تتسسم بالابتكساروالإبـداع والبنـد الخـامس : حققت المشغولة ملامسس

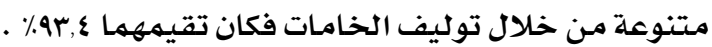
التصعيم السادس :

جدول (^) يوضـح تكرارات إجابات المحكمـين لجميـع بنود تقييم التصميم السـادس

\begin{tabular}{|c|c|c|c|c|c|c|c|c|}
\hline \multirow{2}{*}{ | معاملات الجودة } & \multicolumn{3}{|c|}{ 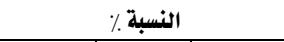 } & \multicolumn{3}{|c|}{ العلد } & \multirow[b]{2}{*}{ |البنود } & \multirow[b]{2}{*}{$\rightarrow$} \\
\hline & غير موافق & موافق إلى & 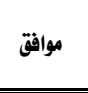 & غوافي & |مدافق إلى & 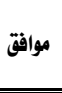 & & \\
\hline$\%$ \% & $\%$ \% १ & $\%\urcorner, 7 \vee$ & $\% \wedge \uparrow$, ๆ & 1 & 1 & ir & |أظهرت رسوم الحاسب ثلاثيــة الأبعـاد جماليـات الرواشـين على & -1 \\
\hline$\%$ & $\% 7,7 v$ & $\%$ & $\%$ • & 1 & $r$ & it & | ثاثلاثية الأبعاد في تصميم الشفولة الاستفادة مـن إمكانيـات رسـوم الحاسب الآلـي & $-r$ \\
\hline$\% 97, \vee$ & $\%$ & $\%$ \%, १V & $\%$ \%r, rr & - & 1 & is & |حققت المشفولة أفكارا تتسم بالابتكار والإبداع & $-r$ \\
\hline$\%$ & $\%$ & $\%$ & $\%$ • & • & $r$ & ir & حققت الشفولة أسس وعناصر التصميي & $\varepsilon$ \\
\hline$\%$ ॥,$\curlyvee$ & $\%$ & $\%$ \%ฯ, IV & $\%$ Vr, rr & - & $\varepsilon$ & 11 & |حققت الشففولة ملامس متنوعة من خلال توليف الخامات & -0 \\
\hline$\%$ /Ar,\& & $\%$ & $\%$ & $\% 97,7 \mathrm{~V}$ & $r$ & $r$ & 1. & |حقت المشفولة أبعادا جمالية ووظيفية & -7 \\
\hline$\% \wedge \uparrow, \vee$ & $\%$ \%, १V & $\%$ & $\%$ Vr, rr & 1 & $r$ & 11 & |تتمشى الششفولة ذات الرؤى التراثية مع اتجاهات العصر الحديث & $-r$ \\
\hline
\end{tabular}

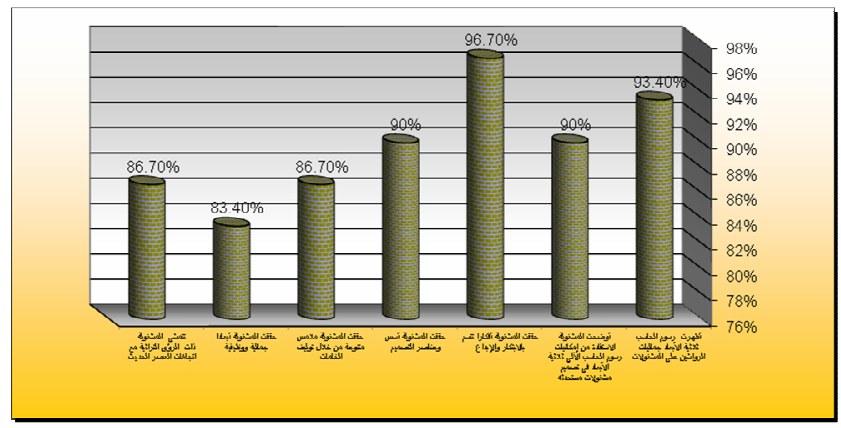

شكل (†) يوضـح معاملات الجودة لجميع بنود تقييهم التصميهم السادس 
من الشكل السابق نستخلص ما يلي :

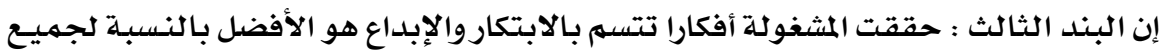

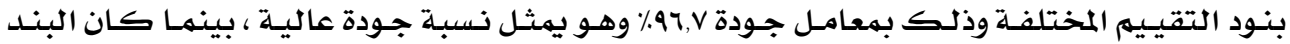

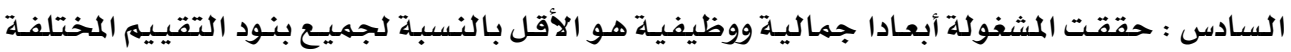

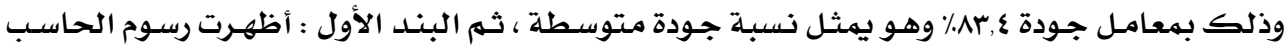

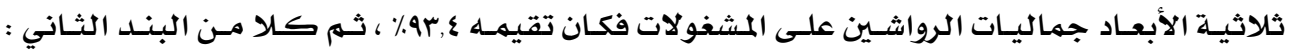

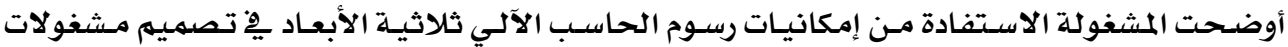

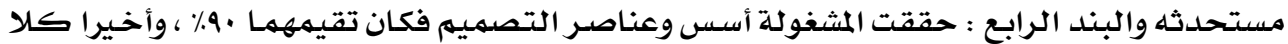

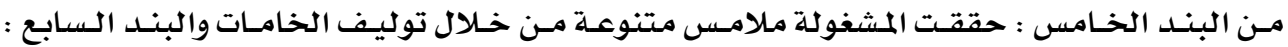

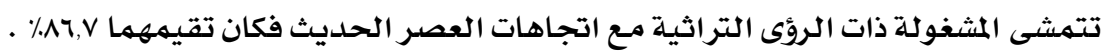
التصميم السابع :

جدول (9) يوضـح تكرارات إجابات المحكمين لجميع بنود تقييم التصميم السابع

\begin{tabular}{|c|c|c|c|c|c|c|c|c|}
\hline \multirow{2}{*}{ و مالمعاملات الجودة } & \multicolumn{3}{|c|}{ 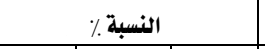 } & \multicolumn{3}{|c|}{ 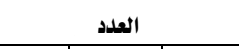 } & \multirow[b]{2}{*}{ 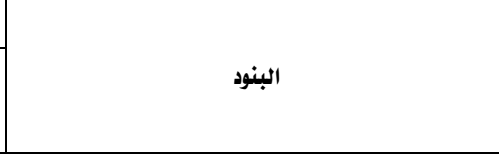 } & \multirow[b]{2}{*}{$\rightarrow$} \\
\hline & غير & موافق إلى ملى مافم & 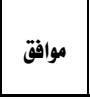 & غير | - غوافق & موافق إلى & 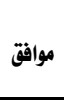 & & \\
\hline$\% 9 १, r$ & $\%$ & $\%$ & $\%$ $/ 9, \pi T$ & - & 1 & \& & | أظظهرت رسوم الحاسب ثلاثيـة الأبعاد جماليـات الرواشيـن على & - \\
\hline$\%$ & $\% / 7,7 v$ & $\%$ & $\% \cdot \Lambda \cdot$ & 1 & r & ir & | ثلاثية الأبعاد في تصعيم مشفولات مستحدثة الاستفادة مـن إمكانيـات رسوم الحاسب الآلسي & r \\
\hline$\%$ \% r ,,$\xi$ & $\% 9,7 v$ & $\%, 7 \mathrm{v}$ & $\%$.AT, Tr & 1 & 1 & ir & |حقت الشغولة أفكارا تتسه بالابتكار والإبداع & $-r$ \\
\hline$\%$ & $\%$ & $\%$ & $\% \cdot \cdot$ & . & . & 10 & |حقت الشفولة أسس وعناصر التصميم & 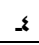 \\
\hline$\% 97, \vee$ & $\%$ & $\%$ & $\%$ \% & . & 1 & \& & حققت الشفولة هلامس متنوعة من خلال توليف الخامات & 0 \\
\hline$\%$ & $\%$ & $\%$ & $\%$. A. & . & $r$ & ir & | حققت الثشفولة أبعادا جمالية ووظيفية & -4 \\
\hline$\% \wedge r, \mathfrak{k}$ & $\%$ & $\%$ & $\% 77,7 v$ & . & 。 & 1. & |تتشى الشفولة ذات الرؤى التراثية مع اتجاهات العصر الحديث & $-\mathrm{r}$ \\
\hline
\end{tabular}

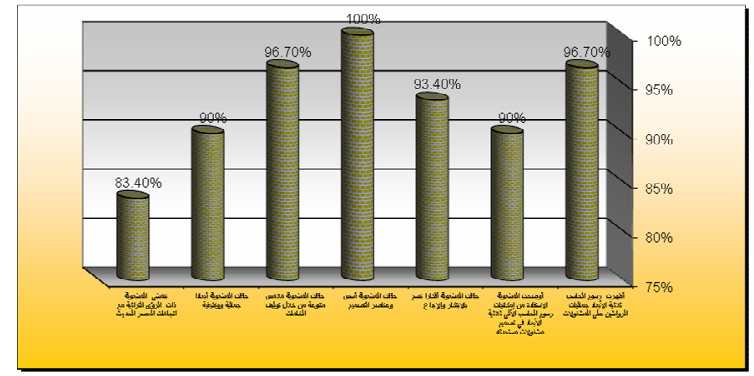

شكل (v) يوضح معاملات الجودة لجميع بنود تقييم التصميم السابع 


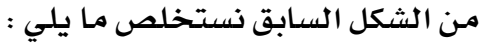

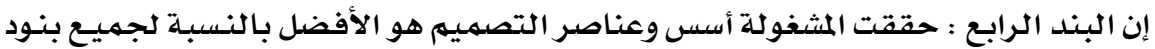

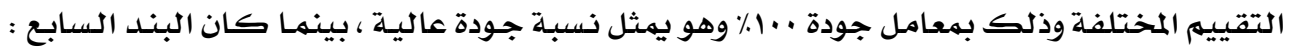

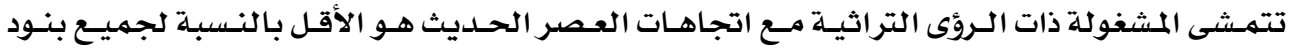

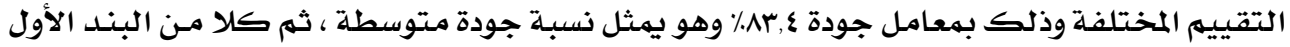

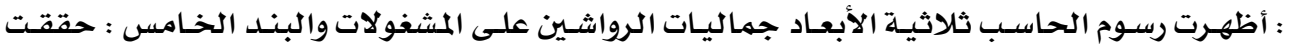

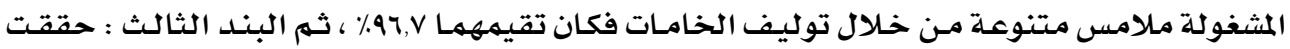

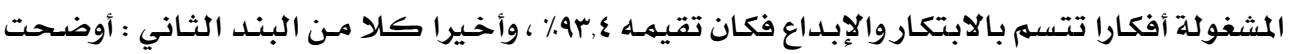

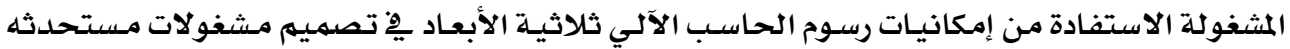

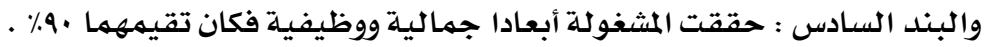
التصميم الثامن : جدول ( ـ ) يوضح تكرارات إجابات المحكمين لجميع بنود تقييم التصميم الثامن

\begin{tabular}{|c|c|c|c|c|c|c|c|c|}
\hline \multirow{2}{*}{ 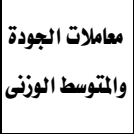 } & \multicolumn{3}{|c|}{ 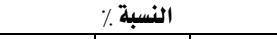 } & \multicolumn{3}{|c|}{ 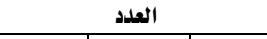 } & \multirow[b]{2}{*}{ 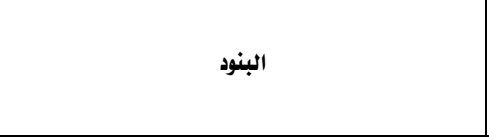 } & \multirow[b]{2}{*}{$\rightarrow$} \\
\hline & 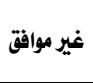 & 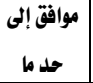 & 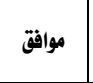 & 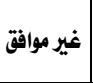 & موافق إلى & 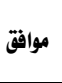 & & \\
\hline 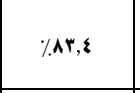 & $\%$ & $\%$ & $\%$ \%7, $7 v$ & r & $r$ & $1 \cdot$ & أظهرت رسوم الحاسب ثلاثية الأبعـاد جماليـات الرواشـين على & -1 \\
\hline$\% \wedge \uparrow, \curlyvee$ & $\%$ & $\%$ \% & $\% \mathrm{Vr}, \mathrm{rr}$ & - & $\xi$ & 11 & | ثلاثية الأبعاد في تصميم مشفولة الاستفادة من إمكانيـات رسـوم الحاسب الآلـي & -r \\
\hline$\%$ & $\%, 7 \mathrm{Yr}$ & $\%$ Ir, rr & $\%$ •. & 1 & $r$ & ir & |حققت الشفولة أفكارا تتسم بالابتكاروالإبداع & $-r$ \\
\hline$\%$ & $\%$ & $\%$ & $\%$ & • & - & 10 & حققت المشفولة أسس وعناصر التصميه & $\varepsilon$ \\
\hline$\% 97, \vee$ & $\%$ & $\%$ \% १V & $\%$ qr, rr & • & 1 & $1 \xi$ & حققت الشفولة ملامس متنوعة من خلال توليف الخامات & -0 \\
\hline$\%$ \% , ६ & $\%$ & $\%$ Ir, rr & $\% \wedge \uparrow, 7 \vee$ & • & $r$ & ir & حققت المشفولة أبعادا جمالية ووظيفية & -7 \\
\hline$\%$ & $\%$ & $\%$ & $\% \wedge^{\circ}$ & • & $r$ & ir & | تلعـشى المـشفولة ذات الــرؤى التراثيـة مـع اتجاهـات العـصر| & $-v$ \\
\hline
\end{tabular}

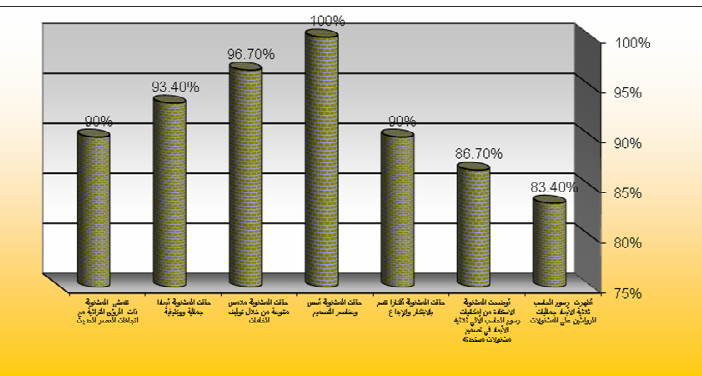

شكل (^) يوضح معاملات الجودة لجميع بنود تقييم التصميم الثامن 
من الشكل السابق نستخلص مـا يلي :

إن البند الرابع : حققت المشغولة أسس وعناصر التصميم هو الأفضل بالنسبة لجميـع بنود

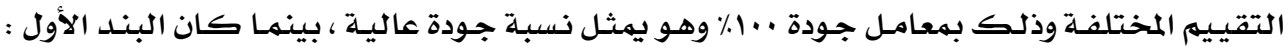

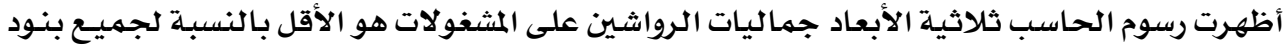

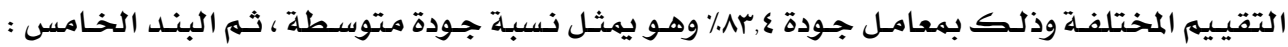

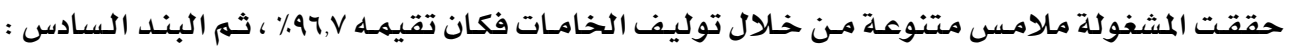

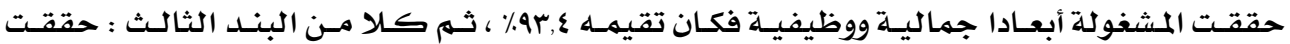

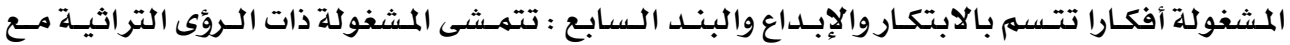

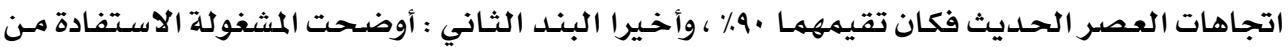

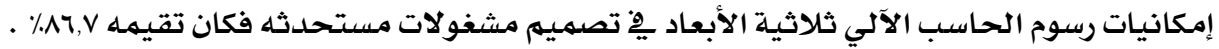
التصميم التاسع :

جدول (11) يوضح تكرارات إجابات المحكمين لجميع بنود تقييم التصميم التاسـع

\begin{tabular}{|c|c|c|c|c|c|c|c|c|}
\hline \multirow{2}{*}{ 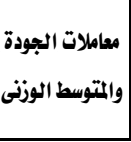 } & \multicolumn{3}{|c|}{ 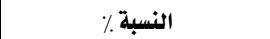 } & \multicolumn{3}{|c|}{ 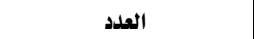 } & \multirow[b]{2}{*}{ 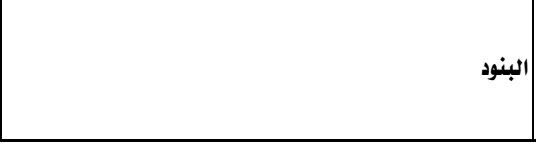 } & \multirow[b]{2}{*}{$\rightarrow$} \\
\hline & غير موافق & موافق إلى مد ما & 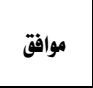 & 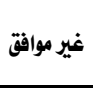 & موافق إلى ما ما & 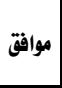 & & \\
\hline$\%$ & $\%$ \%, १V & $\%$ & $\%$. & 1 & $r$ & ir & أظهرت رسوم الجاسب ثلاثية الأبعاد جماليات الرواشين على المشفولات & -1 \\
\hline$\% ৭ 9, \vee$ & $\%$ & $\%$ \%, १V & $\%$ qr, rr & • & 1 & $1 \varepsilon$ & أوأبعاد في تصميه مشفولات مستحولة الاستفادة من إمكانيات رسوم الحاسب الآلـي ثلاثيـة & $-r$ \\
\hline$\%$ & $\%$ \%, IV & $\%$ \% TV & $\% \wedge \uparrow, 7 v$ & 1 & 1 & ir & |حقت المشفولة أفكارا تتسم بالابتكار والإبداع & $-r$ \\
\hline$\% 97, \vee$ & $\%$ & $\%$ ฯ १ & $\%$ qr, rr & • & 1 & $1 \varepsilon$ & | حققت الشفولة أسس وعناصر التصميم & $\varepsilon$ \\
\hline$\%$ & $\%$ & $\%$ & $\%$ & • & - & 10 & حقت الشفولة ملامس متنوعة من خلال توليف الخامات & -0 \\
\hline$\%$ & $\%$ & $\%$ & $\% \cdots$ & • & - & 10 & | حققت الشفولة أبعادا جمالية ووظيفية & -7 \\
\hline$\% 97, \vee$ & $\%$ & $\%$ \%, ๆr & $\%$ qr, rr & - & 1 & $1 \xi$ & تتمشى الششفولة ذات الرؤى التراثية مع اتجاهات العصر الحديث & $-y$ \\
\hline
\end{tabular}

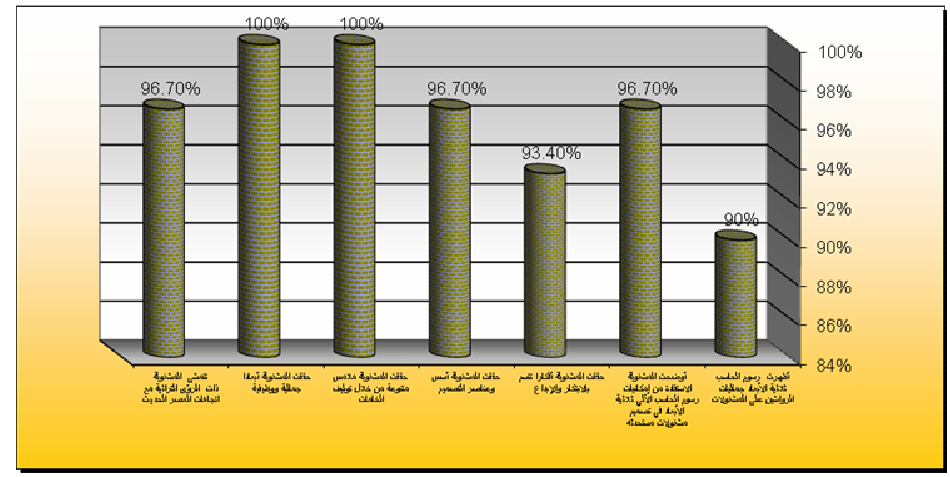

شكل (9) يوضح معاملات الجودة لجميع بنود تقييم التصميم التاسع 


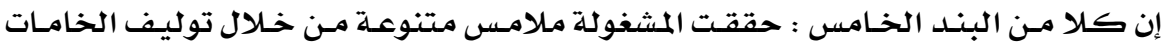

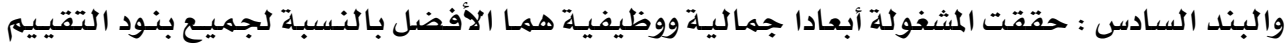

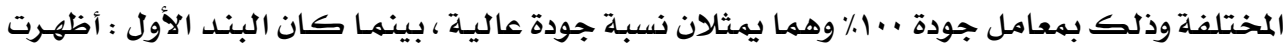

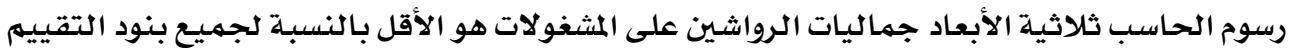

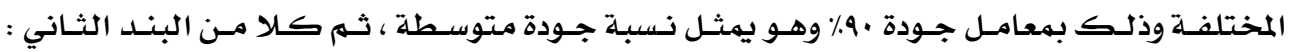

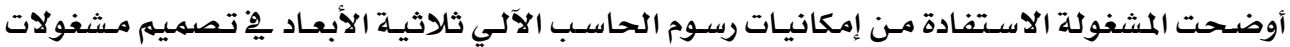

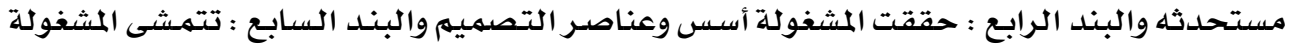

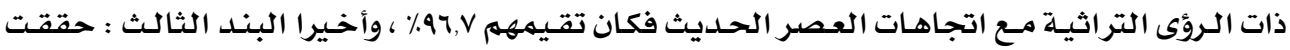

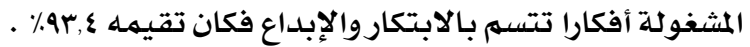
التصميم العاشر :

جدول (r ) يوضح تكرارات إجابات المحكمين لجميع بنود تقييم التصميم العاشر

\begin{tabular}{|c|c|c|c|c|c|c|c|c|}
\hline \multirow{2}{*}{ معاملات الجوسط الوزنى } & \multicolumn{3}{|c|}{ النسبة. } & \multicolumn{3}{|c|}{ العدد العد } & \multirow[b]{2}{*}{ 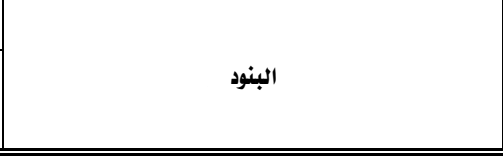 } & \multirow[b]{2}{*}{+} \\
\hline & 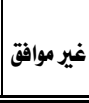 & موافق إلى & 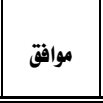 & 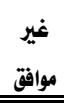 & موافق إلى & موافق & & \\
\hline 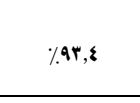 & $\%$ & $\%(r, r r$ & $\%$ \% $7,7 \vee$ & . & r & ir & | الثشفرتلات رسوم الحاسب ثلاثيـة الأبعاد جمائيات الرواشين على & -1 \\
\hline$\%$ & $\%$ & $\%$ & $\%$. & . & $r$ & ir & | ثلاثية الأبعاد في تصعيم مشفولات مستحدثة الاستفادة مـ إمكانيـات رسوم الحاسب الآلسي & $-r$ \\
\hline$\% \wedge \uparrow, \vee$ & $\%$ & \% & $\%(v r, r \psi$ & $r$ & $r$ & 11 & |حقتت الششفولة أفكارا تتسم بالابتكار والإبداع & $-r$ \\
\hline$\%$ /. $\mathrm{r}, \boldsymbol{\varepsilon}$ & $\%, \mathrm{iv}$ & $\%(\mathrm{M}, \mathrm{qv}$ & $\% 17,7 v$ & 1 & $\varepsilon$ & 1. & |حققت الششولة أسس وعناصر التصميم & $\varepsilon$ \\
\hline$\%$ & $\%$ & $\%$ & $\%$ & . & . & 10 & حققت الششفولة ملامس متنوعة من خلال توليف الخامات & $ه$ \\
\hline$\%$ & $\%$ & $\%$ & $\%$ & . & . & 10 & |حقتت الشفولة أبعادا جمالية ووظيفية & -7 \\
\hline$\% 97, v$ & $\%$ & $\%$ \%, 7v & $\%$ /qr, rr & . & 1 & is & تتشى الشفولة ذات الرؤى التراثية مع اتجاهات العصر الحديث | & $-r$ \\
\hline
\end{tabular}

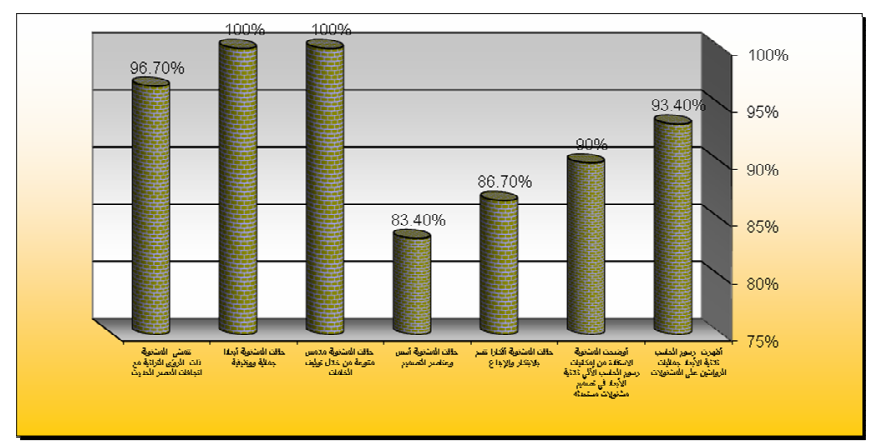

شكل ( . ) يوضح معاملات الجودة لجميع بنود تقييم التصميم العاشر 
من الشكل السابق نستخلص ما يلي :

إن كالا مـن البنـــ الخـامس : حققت المشغولة مـلامس متتنوعـة مـن خـالال توليف الخامـات

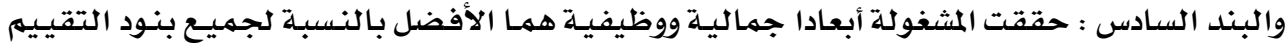

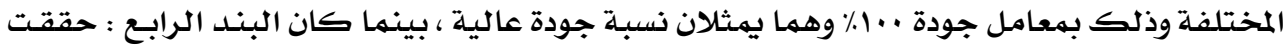

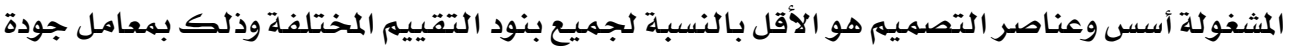

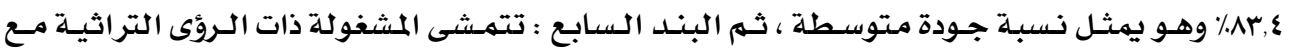

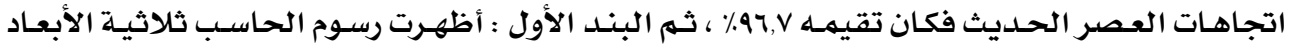

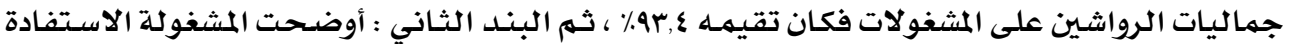

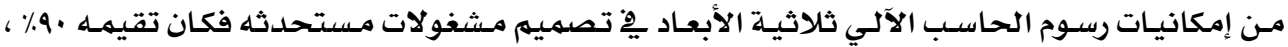

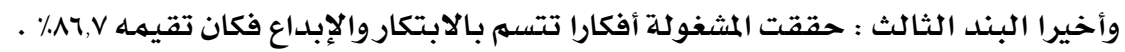

التصميم الحادي عشر :

جدول (rا ) يوضح تكرارات إجابات المحكمين لجميع بنود تقييم التصميم الحادي عشر

\begin{tabular}{|c|c|c|c|c|c|c|c|c|}
\hline \multirow{2}{*}{ 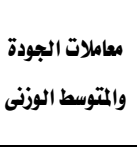 } & \multicolumn{3}{|c|}{ 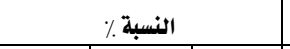 } & \multicolumn{3}{|c|}{ 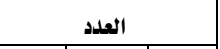 } & \multirow[b]{2}{*}{ 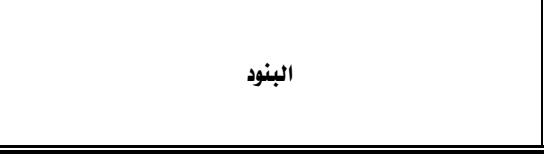 } & \multirow[b]{2}{*}{$\rightarrow$} \\
\hline & 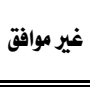 & موافق إلى & موافق & غوافي & |موافق إلى & موافق & & \\
\hline$\%$ \% & $\% \mathrm{~T}, \mathrm{Tr}$ & $\% 7,7 \mathrm{r}$ & /.A7,7v & 1 & 1 & ir & أظهرت رسوم الحاسب ثلاثية الأبعاد جهائليات الرواشين على الششفولات & -1 \\
\hline$\%$ /9. & $\% १, 7 v$ & $\%$ & $\%$. & 1 & r & ir & |الوضعاد في تصفيم مشفولات الاستفادة من إمكانيات رسوم الحاسب الآلـي ثلاثيـة & $-r$ \\
\hline$\% 99, \mathrm{v}$ & $\%$ & $\% 9,7 v$ & $\%$ & . & 1 & is & |حقت الشفولة أفكارا تتسم بالابتكاروالإبداع & ז \\
\hline$\%$ & $\%$ & $\%$ & $\%$ & . & . & 10 & |حقت الششولة أسس وعناصر التصميم & $\varepsilon$ \\
\hline$\%$ & $\%$ & $\%$ & $\%$. & . & $r$ & ir & إسققت الشفولة ملامس متنوعة من خلال توليف الخامات & - \\
\hline$\% \wedge \tau, \mathfrak{\xi}$ & $\%$ & $\%$ & $\% 91, \mathrm{ir}$ & . & 0 & 1. & |حققت الششفولة أبعادا جمالية ووظيفية & -7 \\
\hline$\%$ \%, $\mathfrak{\xi}$ & $\%$ & $\%(\pi, \pi r$ & $\%$ A $7, \mathrm{TV}$ & . & r & ir & تتشى الشفولة ذات الرؤى التراثية مع اتجاهات العصر الحديث & $-y$ \\
\hline
\end{tabular}

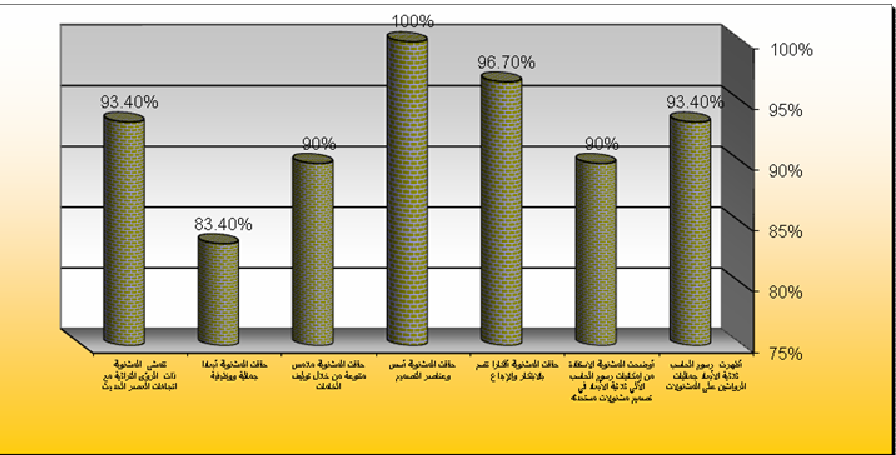

شكل (11) يوضح معاملات الجودة لجميع بنود تقييم التصميم الحادي عشر 


$$
\text { من الشكل السابق نستخلص ما يلي : }
$$

إن البند الرابع : حققت المشغولة أسس وعناصر التصميم هو الأفضل بالنسبة لجميـع بنود

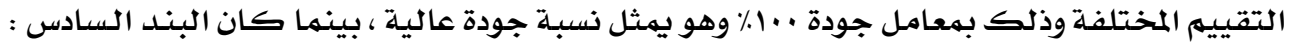

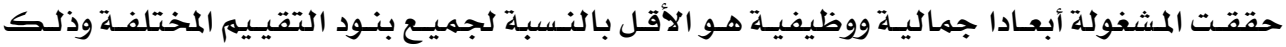

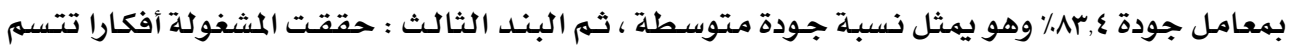

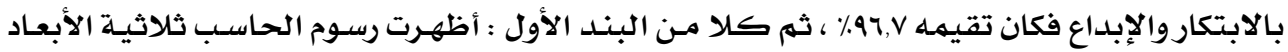

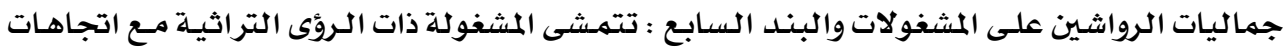

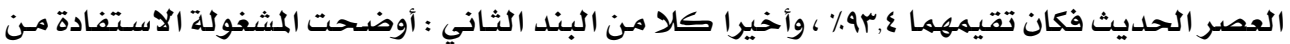

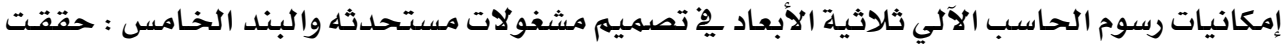

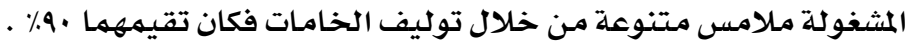
التصميم الثاني عشر :

جدول ( \& ) يوضح تكرارات إجابات المحكمين لجميع بنود تقييم التصميم الثاني عشر

\begin{tabular}{|c|c|c|c|c|c|c|c|c|}
\hline \multirow{2}{*}{ و مالمتوسط الوزنى الجودة } & \multicolumn{3}{|c|}{ النسبة ٪ } & \multicolumn{3}{|c|}{ العدد العد } & \multirow[b]{2}{*}{ البنود البن } & \multirow[b]{2}{*}{$\rightarrow$} \\
\hline & غير موافق & مدومق إلى & موافق & موافق & |مد ما إلى & موافق & & \\
\hline$\% \cdots$ & $\%$ & $\%$ & $\%$ & . & . & 10 & أنهرت رسوم الحاسب ثلاثية الأبعاد جماليات الرواشين على الشفولات & -1 \\
\hline$\% 97, \mathrm{v}$ & $\%$ & $\% 7,7 v$ & $\%$ /qr, r & • & 1 & \& & | الأبعاد في تصعيم الشفولة الاستفادة من إمكانيات رسوم الحاسب الآلـي ثلاثيـة & $-r$ \\
\hline$\% 94, \mathfrak{k}$ & $\%$ \%, $7 \mathrm{r}$ & $\% 7,7 \mathrm{v}$ & $\%$.AT, TV & 1 & 1 & it & | مققت الشفولة أفكارا تتسم بالابتكاروالإبداع & +4 \\
\hline$\%$ & $\%, 7 \mathrm{ir}$ & $\%(r, r r$ & $\%$. & 1 & r & ir & حققت الشفولة أسس وعناصر التصميم & -2 \\
\hline$\%, \wedge \uparrow, \mathrm{v}$ & $\% 7,7 v$ & $\%$ & $\% \mathrm{Vu}, \mathrm{rr}$ & 1 & $r$ & 11 & | جققت الشفولة ملامس متنوعة من خلال توليف الخامات & -0 \\
\hline$\% \wedge \uparrow, v$ & $\%$ & $\%(99, \mathrm{qr}$ & $\% \mathrm{Vr}, \mathrm{rr}$ & . & $\varepsilon$ & 11 & | حققت الشففلة أبعادا جمالية ووظيفية & -7 \\
\hline$\% 97, v$ & $\%$ & $\% 7,7 \mathrm{~V}$ & $\%$ \% & . & 1 & I\& & |تتشى الشفولة ذات الرؤى التراثية مع اتجاهات العصر الحديث & $-v$ \\
\hline
\end{tabular}

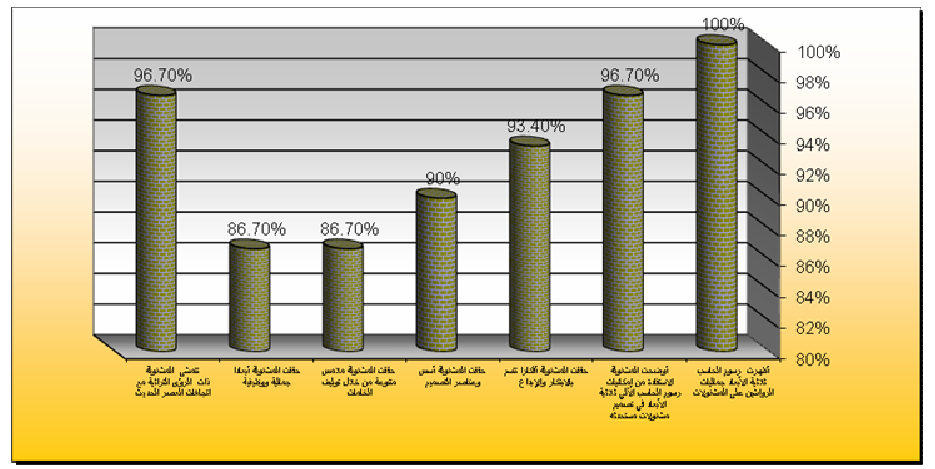

شكل (r ا ) يوضح معاملات الجودة لجميع بنود تقييم التصميم الثاني عشر 
من الشكل السابق نستخلص مـا يلي :

إن البند الأول : أظهرت رسوم الحاسب ثلاثية الأبعاد جماليـات الرواشـين على المشغولات هو الحو

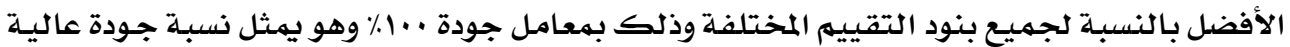

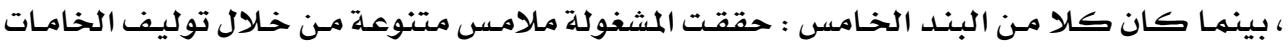

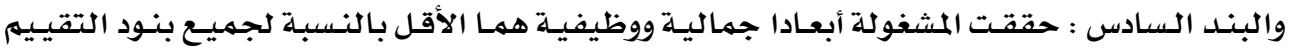

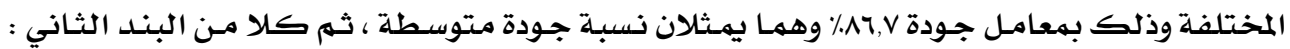

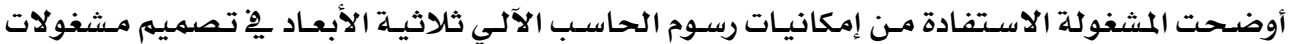

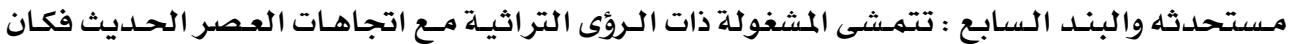

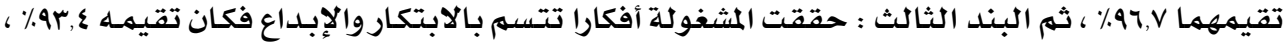

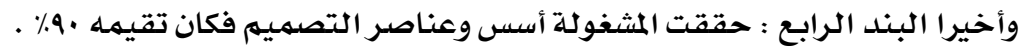
الفرض الثاني :

لا توجد فروق ذات دلالة إحصائية بين المشغولات المبتكرة مـن جماليـات الرواشـين باستتخدام رسوم الحاسب ثلاثية الأبعاد وفقا لأراء المحكمهين وللتحقق من هذا الفرض تم حسـاب تحليل التبـاين لمتوسط درجـات المشغولات المبتكرة مـن

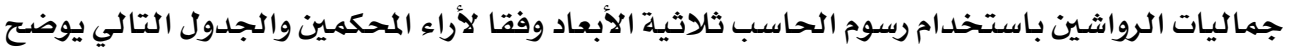

جدول ( 10 ) تحليل التباين لمتوسط درجات المشغولات المبتكرة من جماليات الرواشين باستخدام رسوم الحاسب ثلاثية الأبعاد وفقا لأراء المحكمين

\begin{tabular}{|c|c|c|c|c|c|}
\hline الدلالة & قيمة (ف) & درجات الحرية & متوسط المربعات & مجموع المربعات & \\
\hline \multirow{3}{*}{ غير دال 999 . } & \multirow{2}{*}{ •, YIA } & 11 & $1,0 \leqslant \pi$ & $17,9 Y 1$ & بين المجموعات \\
\hline & & 171 & $\mathrm{v}, 0 \mathrm{Or}$ & IIAE,qrT & داخل المجموعات \\
\hline & & iva & & $\mid r \cdot 1,911$ & المجهموع \\
\hline
\end{tabular}

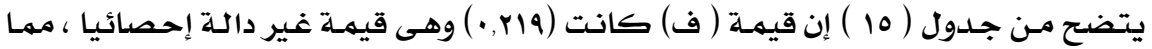

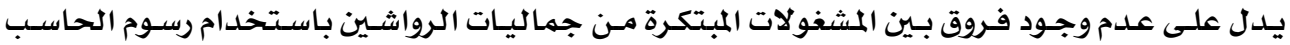

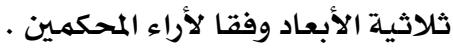

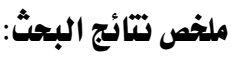

ץ. التعرف على الرواشـين القديمة وزخارفها وأسماء القطع المكونة لها يعتبر مصدر هام للاستلهام

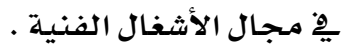

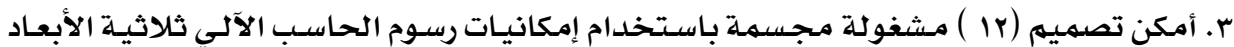

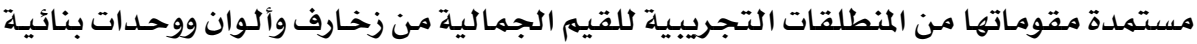

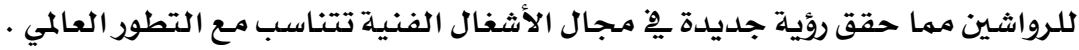




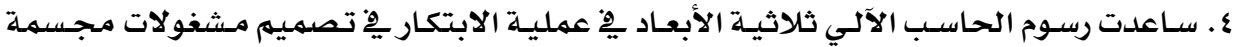

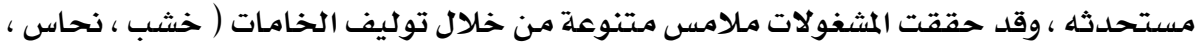

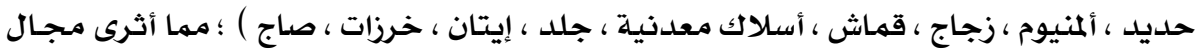

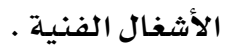

ه. حققت المشغولات أسس وعناصـر التصميهم ، وأعطت أبعـادا جماليـة ووظيفيـة ذات رؤى تراثيـة

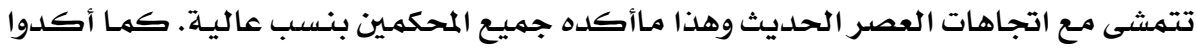

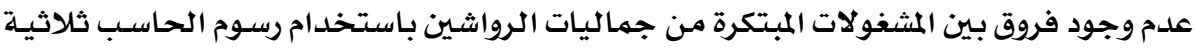
الأبعاد. التتوصيات :

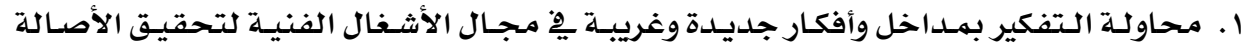

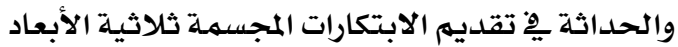

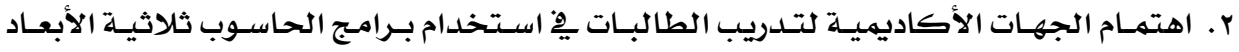

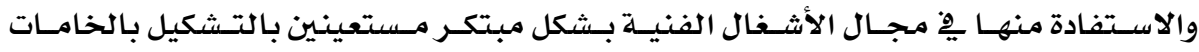

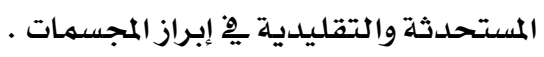


1. جـاد ، وداد عبـد الحلـيم (199V ) : التربيـة الفنيـة ودورها بِ التثقيف بـالفن ، نـدوة علميـة ، كليـة التربيـة

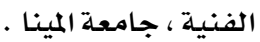

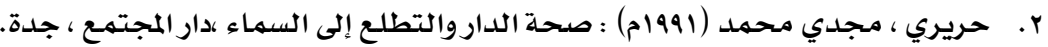

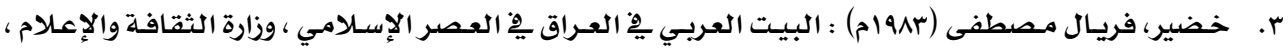

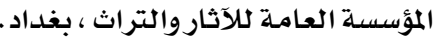

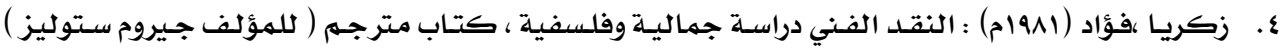
هيئة الكتاب ، القاهرة .

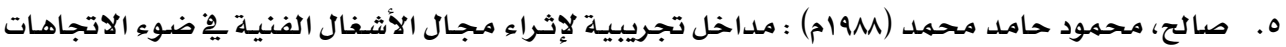

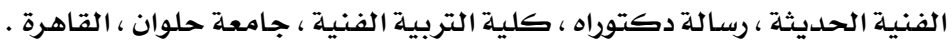

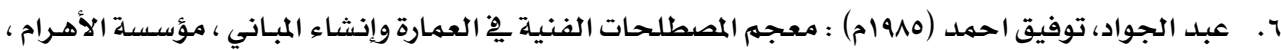
القاهرة .

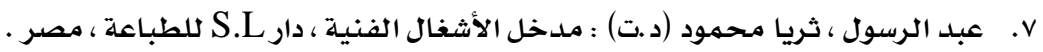

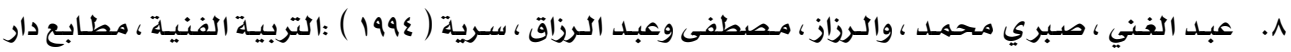
المصاحف ، القاهرة .

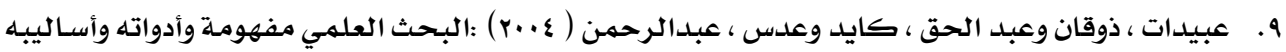
،دار الفكر للطباعة والنشر ، عمان

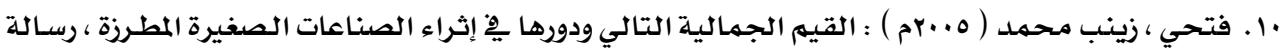

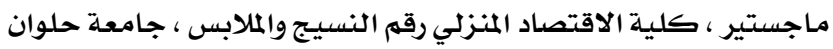

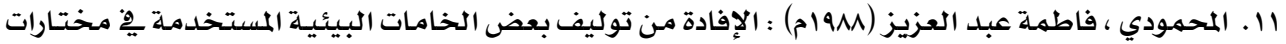
من المشغولات الفنية لعمل مكمهات مبتكرة للزينـة ، رسالة دكتوراه ، كلية التربية الفنيـة ، جامعـة حلـوان ، القاهرة .

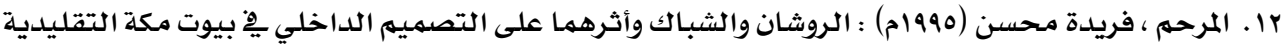

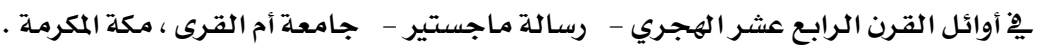

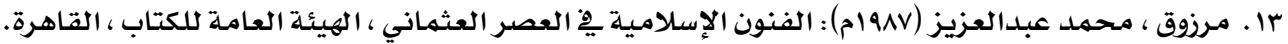

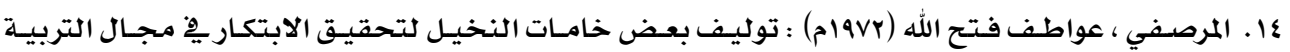

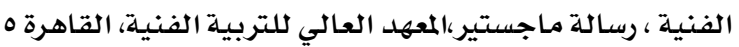

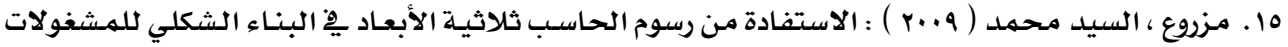

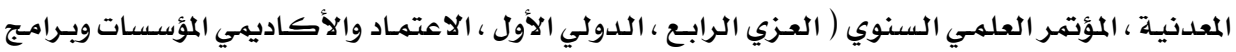

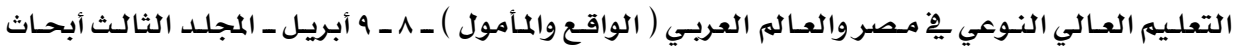
التربية الفنية ـ جامعة المنصورة ، كلية التربية النوعية القاهرة.

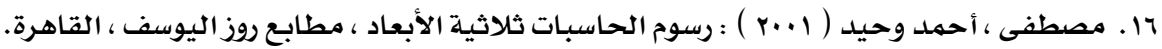

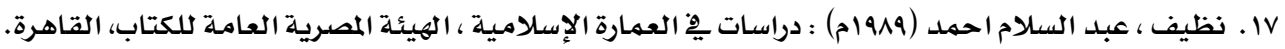
18.Bevlin, m. : Design through discovery, holt Rinehart, new york 1970. 